\title{
Influence of Building Surface Solar Irradiance on Environmental Temperatures in Urban Neighborhoods
}

\author{
Mohammad Heidarinejad ${ }^{1,2}$, Stefan Gracik ${ }^{2}$, Mostapha Sadeghipour Roudsari ${ }^{3}$, Saber Khoshdel Nikkho ${ }^{1}$, Jiying Liu ${ }^{4}$ \\ Kai Liu², George Pitchorov ${ }^{5}$, Jelena Srebric ${ }^{* 1,2}$ \\ ${ }^{1}$ Department of Mechanical Engineering, The University of Maryland, College Park, MD 20740, USA \\ ${ }^{2}$ Department of Mechanical Engineering, The Pennsylvania State University, University Park, PA 16802, USA \\ ${ }^{3}$ School of Design, University of Pennsylvania, Philadelphia, PA 19104, USA \\ ${ }^{4}$ School of Thermal Engineering, Shandong Jianzhu University, Jinan, China 250101 \\ ${ }^{5}$ Technical University of Sofia, Sofia, Bulgaria
}

\begin{abstract}
For buildings located in actual urban neighborhoods, modeling of outdoor airflow with Computational Fluid Dynamics (CFD) requires solar radiation at building surfaces to predict local environmental temperatures. This study conducts a parametric analysis to support the development of coupled simulations of outdoor airflow and solar radiation simulations at building surfaces. To account for different assumptions used in the outdoor modeling, this study uses OpenFOAM CFD and couples it with three different simulation engines, including EnergyPlus, Daysim, and Radiance to predict simulated outdoor solar irradiance for implementation in outdoor CFD simulations. The primary aim of selecting these three simulation engines is to evaluate tradeoffs between the model complexity and accuracy for simulated outdoor solar irradiance for outdoor CFD simulations. Examined parameters include: (i) surface representation with different mesh types, (ii) urban plan area density, and (iii) the impact of simulated solar irradiances on the simulated air temperature and velocity values in the CFD simulations. The study results showed that the surface representation has up to a $7.6 \%$ and $133 \%$ influence on the simulated outdoor global and local solar irradiances, respectively. The surface thermal boundary conditions have up to $1.5^{\circ} \mathrm{C}$ difference on the air temperature and negligible impacts on the air velocity.
\end{abstract}

\section{Introduction}

Land coverage and distribution of the impervious and pervious surfaces changes the rate of heat transfer processes in the built environment. Existence of impervious surface material properties lead to higher levels of heat storage in the total energy budget of urban neighborhoods, and alter the rate of sensible and latent heat transfer rates. For example, impervious exterior surface of buildings can reach high temperature values on sunny days, and this heat is then convected and radiated into the surrounding air and surfaces (Lu \& Weng, 2006). At the large city scale, this phenomenon results in the Urban Heat Island (UHI) effect, which refers to the higher temperatures present in dense urban areas when compared to surrounding rural and suburban regions (Mirzaei, 2015; Touchaei \& Wang, 2015). Many existing studies focus on energy balances of large city areas for the UHI effect, while a few studies examine local temperatures and microclimate (Gracik et al., 2015; Srebric et al., 2015). This study focuses on the urban neighborhood scale to allow modeling of the solar irradiance on the building surfaces and consider the influence of the local urban microclimate on the airflow around a building using Computational Fluid Dynamics (CFD) simulations. Specifically, CFD modeling combined with solar irradiance modeling of building surfaces enables accounting the influence of surface radiative properties on the local air temperatures around buildings in urban

\footnotetext{
${ }^{*}$ Corresponding author. Tel: +1 301405 1624; Fax: +1 3013149477

Email Address: jsrebric@umd.edu
} 
neighborhoods. This study uses open-source software packages including, EnergyPlus, Radiance, and Daysim, to calculate heat fluxes at the building surfaces and to implement these heat fluxes in the outdoor CFD simulations with OpenFOAM solver. This approach allows prediction of local air temperatures dependent on building surface material properties in the context of an urban neighborhood.

The combined airflow and solar irradiance modeling on the building surfaces at the urban neighborhood scale requires solving systems of partial differential equations. Three different methods, including analytical, experimental, and numerical could solve this system of equations. Analytical modeling involves the direct solution method using assumptions to reduce the system of equations to a closed form. Since this is only possible on simple geometries, it is not a useful technique for solving the combined outdoor airflow and solar irradiance in actual urban neighborhoods. Experimental and numerical modeling methods allow solutions of this equation system representing actual neighborhoods. Experimental methods entail wind tunnel measurements or placement of sensors in the urban environment to measure air temperature, wind velocity, and solar intensity among other variables (Shahrestani et al., 2013; Srebric et al., 2015). The experimental methods accurately represent local temperatures and wind speeds, but the measurements are limited to areas covered by the sensors. Initial and calibration costs as well as accuracy of the sensors are another limiting factor in the experimental method. Due to these limitations, the numerical simulation method is an attractive technique for resolving the temperature and velocity fields in urban areas (Ashie et al., 1999; Mirzaei \& Haghighat, 2010). Nevertheless, the experimental method, such as the wind tunnel or in-situ experiments, is valuable in validating results from a numerical model (Defraeye et al., 2010). Overall, among the three methods, numerical method can offer insights for the early design stage of buildings because it allows a parametric study of the inputs, and provide performance predictions of buildings and urban neighborhoods. Therefore, this study uses the numerical method to calculate building exterior surface heat fluxes as thermal boundary conditions for the outdoor airflow CFD simulations.

Building design practice is gradually moving toward using integrated simulation tools to perform simulations for airflow, radiation, daylight, and building energy consumption of the buildings and perform parametric analysis for building sustainable urban neighborhoods (Stavrakakis et al., 2012; Taleb \& Musleh, 2015). However, there is a need for additional inputs from the building industry and building research community to support and increase the market share of this integrated simulation approach. In practice, building performance predictions use airflow, radiation, daylight, and building energy consumption separately. However, these heat and mass transfer processes are not separated from each other, meaning there is a need to include coupled simulations to enable better design of buildings. This integration of tools will support the design of green buildings and sustainable cities (Fan et al., 2013). Use of simulation tools to design buildings does not necessarily lead to better representation of actual heat and mass transfer processes of the building performance or faster building design. Without consideration of the design need, each simulation tool could overconsume the computational and human resources. As an example, a complete integration of an outdoor solar radiation simulation with a CFD simulation for a neighborhood requires a substantial amount of resources and may not lead to accurate simulation results. Limitation and benefits of using different tools to calculate outdoor solar radiation on the building surfaces is an important input for the outdoor airflow CFD simulations. This input allows a better representation of heat fluxes or exterior building surface temperatures for the CFD simulations. Therefore, this study conducts a parametric analysis to elaborate:

(1) Use of EnergyPlus, Radiance, and Daysim to calculate outdoor solar radiation on the building surfaces for using in the outdoor airflow CFD simulations

(2) Impacts of using different assumptions to represent the surfaces for buildings located in urban neighborhoods

(3) Benefits and limitation of utilizing simulated solar irradiances for implementation in the airflow simulations

(4) Quantifying influence of different solar irradiance simulation tools on the airflow temperature and velocity variations 


\section{Combined airflow and solar irradiance modeling}

This study reviewed outdoor airflow simulations around buildings located in urban neighborhoods, and the implication of using different thermal boundary conditions for the outdoor airflow CFD simulations. A laborintensive approach uses the on-site measurements to implement the surface temperature readings as boundary conditions for the airflow CFD simulations (Fintikakis et al., 2011). In the design of sustainable urban neighborhoods, this approach would require significant number of measurement data points. Therefore, the present study focuses on irradiance simulations as an alternative source of thermal boundary conditions for outdoor CFD simulations of urban neighborhoods that could provide opportunities to design more sustainable neighborhoods.

\subsection{Outdoor airflow simulations}

Previous outdoor airflow CFD studies at the microscale analyzed design in the urban environment such as: (1) examination of outdoor thermal comfort, (2) assessment of urban heat island, and (3) calculation of outdoor local temperature. CFD has been used to examine outdoor thermal comfort (Huang et al., 2005; Mochida \& Lun, 2008), pollutant dispersion (Baik et al., 2009; Xie et al., 2005), greenspace effect on urban heat islands (Ashie et al., 1999; Takahashi et al., 2004), local temperature effect on Coefficient of Performance (COP) (Chow et al., 2000; Gracik et al., 2015), and effect of urban density on outdoor Convective Heat Transfer Coefficient (CHTC) (Liu, Heidarinejad, Gracik, \& Srebric, 2015; Liu et al., 2013). Many microscale studies adhere to similar simulation setup standards, and several institutions have compiled their own set of standards, such as the Architectural Institute of Japan (Tominaga et al., 2008) which heavily references results of a European COST (Cooperation in Science and Technology) 732 Action Network (Franke et al., 2007). In terms of the implementation of the thermal condition on the exterior surfaces, most of the existing simulations relied on the radiation modules available in the commercial CFD software packages such as Solar Position and Intensity Code (Solpos) implemented in Fluent or IMMERSOL in PHOENICS (Liu, Heidarinejad, Gracik, Srebric, et al., 2015; Stavrakakis et al., 2012; Taleb \& Musleh, 2015). Other simulations used simplified urban neighborhood configurations in the urban scale representation of neighborhoods, such as the urban canopy models (Touchaei \& Wang, 2015), allowing these studies to benefit from the existing urban morphology parameters. Therefore, based on the conducted literature review, the current study uses the simplified urban neighborhoods used in the literature as case studies to represent the urban neighborhoods. The selected case studies in this study include different urban neighborhood morphologies.

\subsection{Thermal boundary conditions for outdoor airflow simulations}

Boundary condition for building surfaces in the urban neighborhood is a crucial aspect of modeling airflow around the buildings. Thermal boundary conditions in the urban neighborhoods are constantly changing due to dynamic occurrence of the heat transfer processes, meaning a simple steady state solution may not accurately represent the thermal boundary condition. Thermal mass of the building material is another large factor in determining the heat flux from the building. Previous urban studies encompass a wide variety of boundary conditions. Existing studies used different methods to account for the building surface temperatures including: (1) idealized boundary conditions such as fixed wall temperatures (Xie et al., 2005), (2) an improvement of the simplified 1D heat flux calculations such as the objective hysteresis model (Arnfield \& Grimmond, 1998; Grimmond et al., 1991), (3) 1D heat flux calculations such as the Conductive Transfer Function (CTF) (Asawa et al., 2008; Giaconia \& Orioli, 2000; Spitler, 2009; Takahashi et al., 2004), and (4) the use of energy simulation and ray tracing tools that consider the thermal mass of the building (Bueno et al., 2011; Gülten et al.; Nazarian \& Kleissl, 2015; Yaghoobian \& Kleissl, 2012).

The first method is the simplest, and it implies that at a steady state, building surfaces release the absorbed solar heat flux into the atmosphere by convection and radiation, assuming that the building surfaces are hotter than the atmosphere. Fluid motion and the transfer of heat are interdependent, and fluid motion is highly dependent on the neighborhood morphology. Empirical equations can account for the fluid motion in generalized neighborhood morphology, but these equations cannot represent local variability of fluid motion with associated local environmental temperatures at the microscale. A simple method of calculating the heat fluxes from building surfaces is to multiply the net incoming radiation by an empirically derived coefficient. The result is a linear relationship 
between incoming solar radiation and the stored heat flux (the resultant flux into the atmosphere) (Oke et al., 1981). Despite being simplistic, the model produced acceptable results for daylong time scales. However, the results were poor when applied to hourly time steps (Oke et al., 1981). Constantly changing atmospheric and solar conditions coupled with the high thermal mass component of common building materials ensures that the steady state solution is not often a viable description of the system.

Analytical solutions have been implemented for the calculation of temperature distribution in the building envelope, in the form of CTF (Giaconia \& Orioli, 2000), and the result of separation of variable analysis for partial differential equations (de Monte, 2000). EnergyPlus benefits from CTF for the building energy simulations. The objective hysteresis model combines the net incident radiation with a time derivative and empirically derived coefficients to attempt to account for the thermal mass for several different urban landscapes (Grimmond et al., 1991). This model is similar to the first method in that the input is the net incident radiation on the surface of interest considering empirical derived coefficients. The model features three coefficients, and takes into account the time derivative of solar radiation (hour time step) in an attempt to account for some effects of thermal storage. The coefficients in this model represent empirical variables obtained for different surface materials. Furthermore, another practical approach uses simulation tools to calculate the surface temperature using the outdoor solar irradiance (Gracik et al., 2015; Nazarian \& Kleissl, 2015). For example, EnergyPlus considers surrounding buildings as blockage in the calculation of solar irradiance. Implementation of this method in DesignBuilder, an interface for the EnergyPlus simulation engine, showed its implications on the energy consumption of buildings (Stupka \& Kennedy, 2010). More recent building canopy models include the effects of building energy consumption into the model to increase accuracy of the predicted environmental temperatures (Yaghoobian \& Kleissl, 2012). These studies did not provide recommendations on the assumptions that are required to consider real-time outdoor solar radiation in the implementation of outdoor airflow CFD simulations. Therefore, this study aims to review limitations and benefits of using outdoor solar radiation and provides a set of recommendations to deploy solar radiation results as temperature boundary conditions for outdoor airflow CFD simulations.

\subsection{Benefits and limitations of outdoor solar radiation simulations for CFD simulations}

Application of the exterior surface solar irradiance values from the EnergyPlus, Daysim, and Radiance simulations could provide inputs for the CFD simulations. Existing studies shown that Radiance or Daysim calculate outdoor solar radiation more accurately for a specific outdoor condition (Ramos \& Ghisi, 2010). The Radiance/Daysim is successfully used to calculate outdoor solar availability for buildings located in urban environments (Compagnon, 2004; Kämpf et al., 2010; Strømann-Andersen \& Sattrup, 2011). However, none of the reviewed studies performed a parametric analysis for the commonly used urban neighborhood morphologies in the airflow simulations. This is an important evaluation step of the Radiance or Daysim simulation results for their implementation in the airflow CFD simulations. To integrate the outdoor solar radiation results into CFD simulations, it is required to consider thermal mass of the buildings and use surface temperatures as the boundary conditions for CFD simulations. Furthermore, there is a need to consider an additional level of complexity in order to convert the calculated heat fluxes as temperature boundary conditions for the CFD simulations, requiring the calculations of conduction heat transfer in the building walls.

\section{Research methodology}

The problem domain in urban environments greatly varies in scale and feature many spatial/temporal scales interacting physical systems. Therefore, to enable a systematic study, this study assesses impacts of the urban neighborhood morphology based on the computational effort, model complexity, and effort needed for implementation of outdoor solar irradiance in the airflow CFD simulation and establish the level of accuracy required. This section provides three steps used in this study, allowing this study and future studies to conduct a parametric study. 
In the first step, this study considers six different urban plan area densities representing different urban neighborhoods to evaluate influence on the surrounding buildings on the building of interest (Liu et al., 2013). Urban plan area density, the ratio of built area to total area, represents the influence of urbanization in cities. The main reason to select the urban plan area density as the main urban morphology parameter is to allow a nondimensional assessment for the results of this study (Srebric et al., 2015). This selection enables urban planners and other experts to replicate the results of the simulations and directly compare the results. Traditionally, the urban density represented a parameter for the urban canyon and outdoor CFD studies to provide replicable results for convective heat transfer, temperature validation, and velocity validation.

Then, three different simulation tools for the outdoor solar irradiance, including Radiance, Daysim, and EnergyPlus, are utilized. This selection of the solar irradiance allows for evaluation of performing a parametric study with different test points for the implementation in the outdoor airflow simulations. These simulation engines use back ray tracing to calculate the solar irradiance on the building surfaces. The models used in these simulation engines vary in terms of calculation of solar position, contribution of the sky condition to the surfaces, and the calculation of the receiving solar irradiance on the building surfaces based on the shaded and un-shaded areas.

In the third step, the results of this study are deployed in the OpenFOAM CFD simulations as a proof of concepts. Benefits and limitations of EnergyPlus, Daysim, and Radiance simulation results for the CFD simulations are summarized.

\subsection{Step 1: Urban Geometry}

This study considers six different plan area densities $\left(\lambda_{\mathrm{p}}\right)$, including $0.04,0.063,0.11,0.16,0.25,0.44$, to exemplify different urban densities (Liu et al., 2013). Figure 1 shows the configuration of two different urban neighborhoods with urban plan area densities $\left(\lambda_{\mathrm{p}}\right)$ of 0.04 and 0.44 . Urban plan area density of 0.04 represents the least dense urban neighborhood meaning the surrounding buildings have insignificant influence on the building of interest. The urban plan area density of 0.44 represents the densest urban environment enabling assessment of situations in which the building of interest is partially shaded due to the influence of surrounding buildings.

The selected urban morphologies in this study represent commonly simulated urban neighborhoods in the outdoor airflow CFD simulations. Consideration of different urban plan area densities allows assessment of impacts of urban neighborhood on the solar incident irradiance on the building surfaces. The current study uses EnergyPlus, Radiance, and Daysim to evaluate the impacts of the urban neighborhood with varying urban plan area density to consider influence of the surrounding buildings on the building of interest.

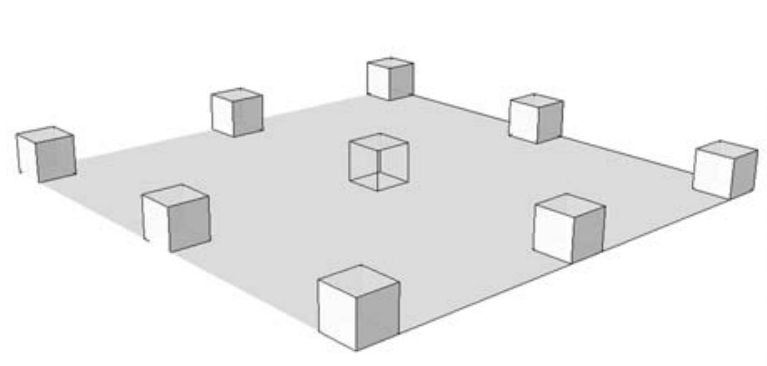

(a)

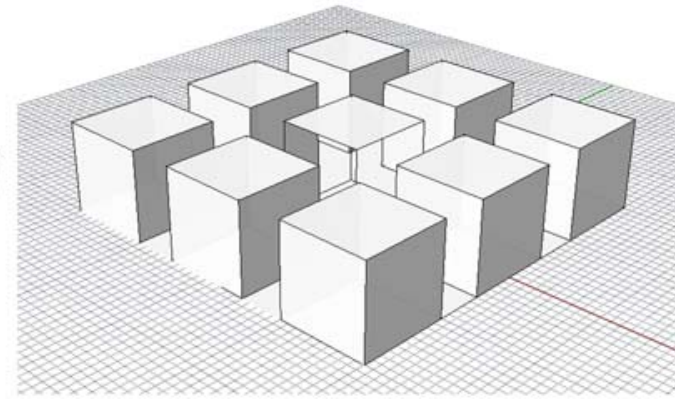

(b)

Figure 1. Two urban neighborhoods with urban plan area density of (a) 0.04 and (b) 0.44 


\subsection{Step 2: Solar Radiation}

Three different simulation tools, including Radiance, Daysim, and EnergyPlus are able to calculate surface incident radiation and shades in an urban environment. Radiance and Daysim require considering test points on the surfaces. Consideration of test points represents number of sensors required for the backward ray tracing calculation of the solar irradiance incident. These tools are designed to consider spatial distribution of the solar irradiance on the building surfaces. To assess impacts of the test points, contribution of the sun position and interactions of the building surfaces and sun angle on the outdoor solar irradiance calculations. This study considers the following steps:

1. Consider three different days including June 21, September 21, and December 21, during the year to repesent days with different sun angle that creates different solar irradiance contributions to the building surfaces. September 21 represents the fall equinox while the June 21 and Decmber 21 represent the summer and winter solstice, respectively.

2. Select three representative hours, including $9 \mathrm{am}, 12 \mathrm{pm}$, and $3 \mathrm{pm}$, during each of the selected days to consider interactions of the sun angle and building surfaces throughout the selected days.

3. Assess impacts of the selecting three different building surface patch sizes, including $1 \mathrm{~m} \times 1 \mathrm{~m}, 2 \mathrm{~m} \times 1.5 \mathrm{~m}$, and $10 \mathrm{~m} \times 3 \mathrm{~m}$ (one patch per floor), to calcualte the outdoor solar irradiance on the building surfaces.

4. Select Chicago, IL as the main city to calcualte the solar irradiances.

Figure 2 illustrates the test points used in this study. Figure 3 provides the simulation results for surface heat fluxes for the two simulated urban plan area densities. Selection of these parameters determines accuracy and computational time of the backward ray tracing in Radiance. Radiance and Daysim models use three bounces for the simulations and the other influential Radiance parameters, including "aa", "as", and "ar", which are set to 0.2, 2048, and 64, respectively. Parameter "aa" is the ambient accuracy, and it determines the maximum allowable error in the indirect irradiance interpolation. Parameter "as" is the ambient super-samples that considers number of extra rays required in the sample areas. Parameter "ar" is the ambient resolution, and this parameter sets sets the distance between ambient calculations by considering different factors. In addition, the number of bounces determines the maximum number of diffuses bounces required for the indirect calculation. Radiance documentations offer details on different values for the range of input variables ("Daylighting calculation options," 2015; Mardaljevic, 2011; "Radiance setting rendering options," 2015).

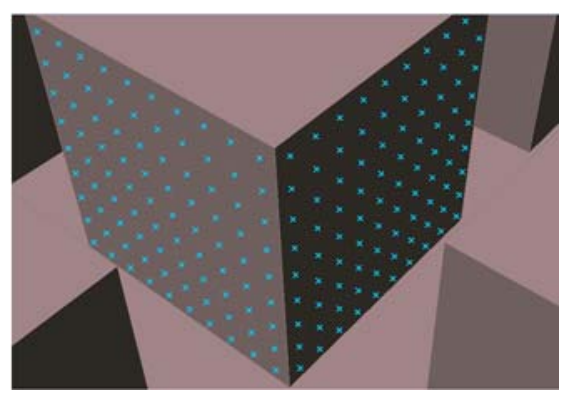

(a)

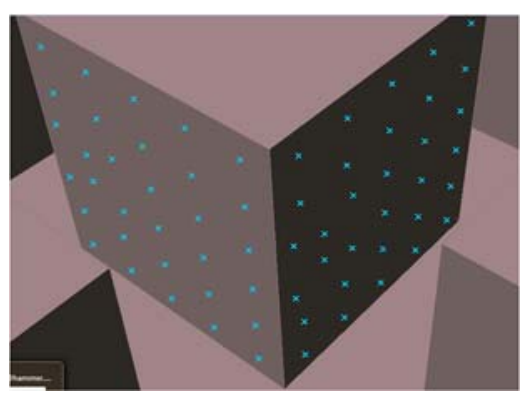

(b)

Figure 2. Test points for the buildings simulated in Radiance and Daysim with spacing of: (a) $1 \mathrm{~m}$ and (b) $2 \mathrm{~m}$ 

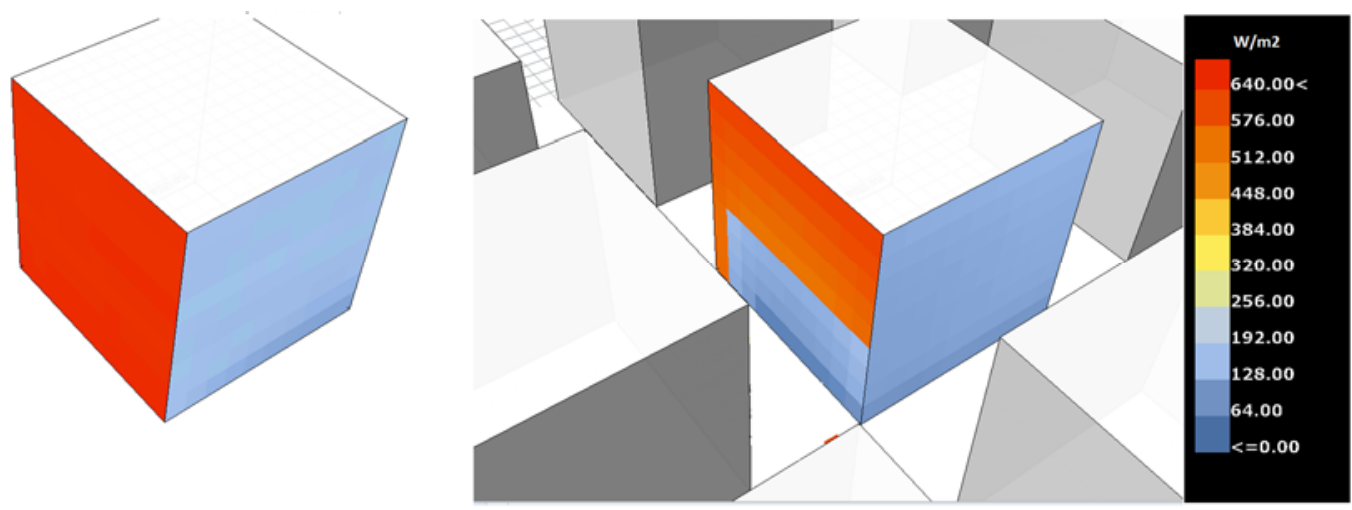

Figure 3. Sample of the Radiance visualization for two different plan area densities

As an alternative to Radiance and Daysim, EnergyPlus considers only one surface per façade for the calculation of the solar irradiance on the building surfaces. In addition, EnergyPlus building models are typically developed for an individual building without consideration of the surrounding buildings. To incorporate a more accurate representation and comparison of the solar irradiance on the building surfaces, this study considers three different approaches to create smaller patches on the building surfaces in the EnergyPlus building models. Figure 4 illustrates three different detailed representation of surfaces in the simulation. While Figure 4-a and Figure 4-b represent a similar pattern of the Daysim and Radiance with $1 \mathrm{~m}$ and $2 \mathrm{~m}$ test points, Figure 4-c considers one surface per building floor.

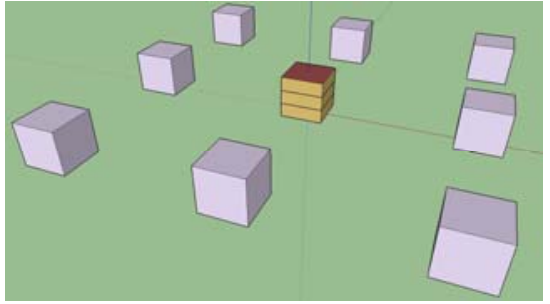

(a)

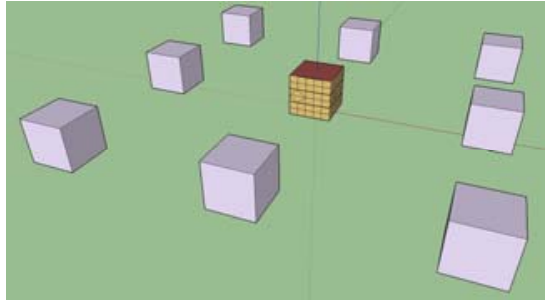

(b)

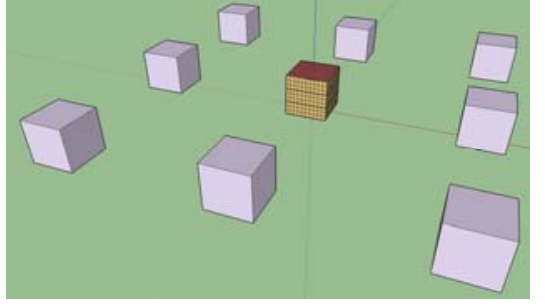

(c)

Figure 4. Three different of representation of building surfaces in EnergyPlus for $\lambda_{\mathrm{p}}=\mathbf{0 . 0 6 3}$ : (a) One per floor (10m $\left.\times 3 \mathrm{~m}\right)$, (b) $2 \mathrm{~m} \times 1.5 \mathrm{~m}$, and (c) $1 \mathrm{~m} \times 1 \mathrm{~m}$

To clearly show the selected patches in this study, Figure 5 illustrates the top view of the patches when the building surfaces are projected in the horizontal view. Patches 1 through 4, patches 5 through 8, and patches 9 through 12 represent the first floor, second floor, and third floor, respectively. Figure 5 also illustrates three different representations of the surfaces. In the first representation, each surface has test points with $1 \mathrm{~m} \times 1 \mathrm{~m}$ distances. The distance between the second representation is $2 \mathrm{~m} \times 1.5$. In the third representation, each patch size is $10 \mathrm{~m} \times 3 \mathrm{~m}$. Therefore, in the third representation, each patch considers the one surface per floor assumption. In this case, there are 3 horizontal walls stacked vertically over each other per façade, totaling 12 horizontal walls for a three story building in the EnergyPlus building energy model. This feature works for the considered urban neighborhoods in this study. 


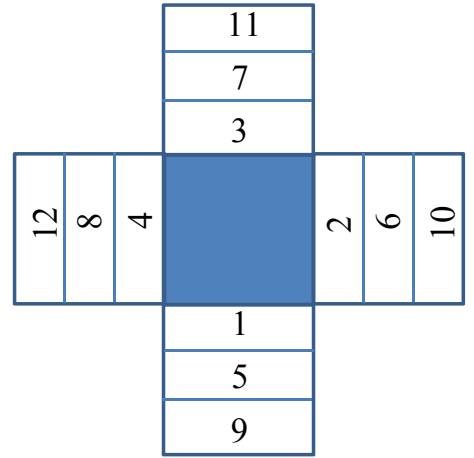

Patch 1

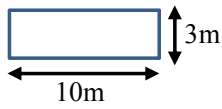

Representation 1
- Patches 1 through 4 indicate first floor patches

- Patches 5 through 8 indicate second floor patches

- Patches 9 through 12 indicate third floor patches

- The sun directly irradiates to patches 4,8 , and 12

Figure 5. Representation of the patches used in this study for the comparisons

This study suggests two options to include the influence of the solar radiation from the surrounding buildings in EnergyPlus building models: (1) Consideration of all of the buildings into a single Input Dictionary File (IDF) file and (2) Consideration of the surrounding building as shading objects in the IDF file. The first option allows to simulate the entire buildings in the urban neighborhood while it requires additional work to organize surfaces. The second option works faster while does not provide additional information about the surrounding buildings. Also, in terms of the number of bounces, EnergyPlus offers different methods to calculate the exterior radiation ("EnergyPlus Engineering Reference," 2014). For example, 'FullInteriorAndExteriorWithReflections` represents the actual phenomena in the urban neighborhoods where the solar beams emitted from the sun and reflected from the surfaces interact with each other.

\section{Solar irradiance results}

This section assesses the results of different solar irradiance values on the building surfaces for different test point sizes, representative days, and different urban neighborhood morphology. This section entails evaluation of different days for (i) EnergyPlus patch sizes, (ii) Radiance and Daysim patch sizes, (iii) local solar irradiances for different tools, (iv) global averaged solar irradiances for different tools, and (v) impacts of height variations.

\subsection{EnergyPlus patch sizes}

Figure 6 illustrates the distribution of local solar irradiance values on the twelve building surfaces for June 21 and September 21 at 3PM for urban plan area densities of 0.04 and 0.44 using the three patch sizes of $1 \mathrm{~m} \times 1 \mathrm{~m}, 2 \mathrm{~m} \times$ $1.5 \mathrm{~m}$, and $10 \mathrm{~m} \times 3 \mathrm{~m}$. Consideration of these combinations allow to assess the impact of the urban plan area density, angle of the sun to the building surfaces, and patch sizes on the simulated results. Patch sizes of $1 \mathrm{~m} \times 1 \mathrm{~m}$ and $2 \mathrm{~m} \times$ $1.5 \mathrm{~m}$ show a similar pattern for all the surfaces, suggesting there are no significant impacts in the selection of these two patch sizes. One important note is that except June 21 at 3PM, as it is shown in Figure 6(a), patch sizes of $1 \mathrm{~m} \times$ $1 \mathrm{~m}$ and $2 \mathrm{~m} \times 1.5 \mathrm{~m}$ show a different pattern than the patch sizes of $10 \mathrm{~m} \times 3 \mathrm{~m}$. Also, a comparison between June 21 and September 21 suggests that when the sun angle to the building is low, September 21, there is a consistent difference between results of the large patch sizes compared to the small patch sizes. 
June 21 at $3 P M, \lambda p=0.04$

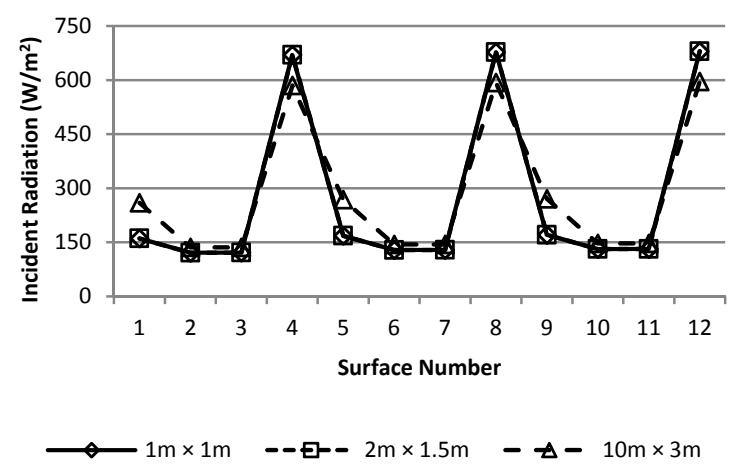

(a)

June 21 at $3 P M, \lambda p=0.44$

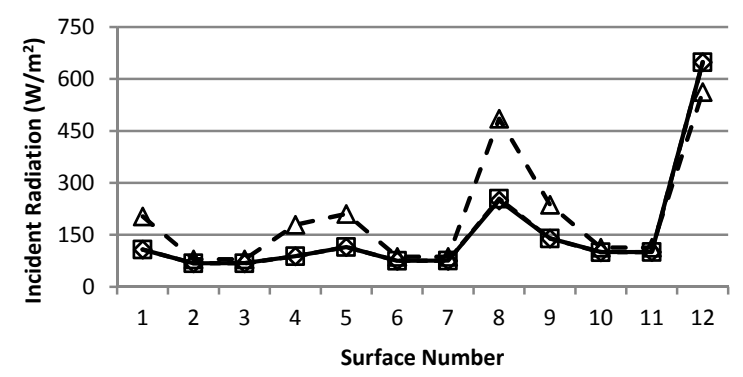

$\longrightarrow 1 \mathrm{~m} \times 1 \mathrm{~m}(\mathrm{E}+)--\boxminus-2 \mathrm{~m} \times 1.5 \mathrm{~m}(\mathrm{E}+)-\Delta-10 \mathrm{~m} \times 3 \mathrm{~m}(\mathrm{E}+)$

(c)
September 21 at $3 P M, \lambda p=0.04$

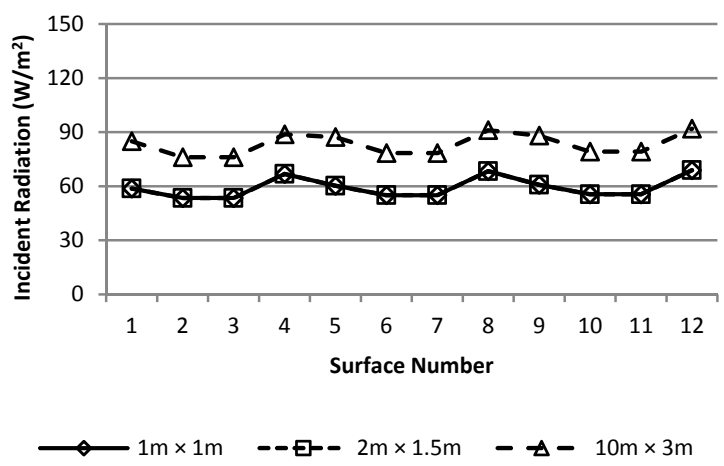

(b)

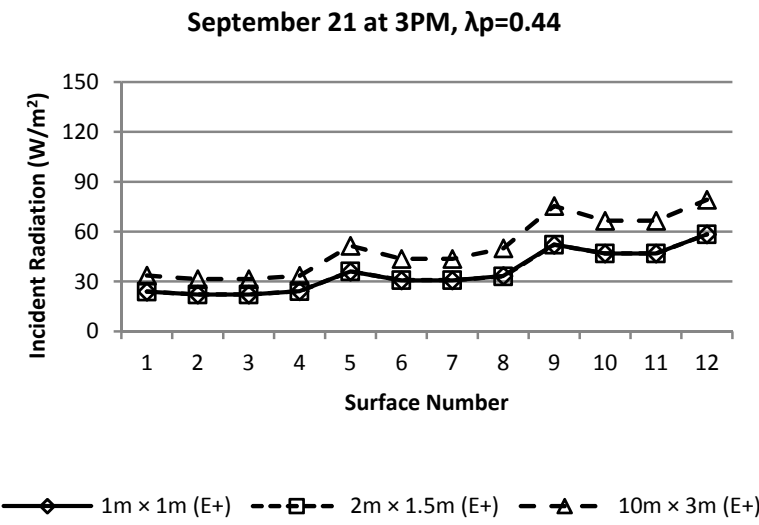

(d)

Figure 6. Solar irradiance distribution on the building surfaces for two different urban plan area densities and two representative time for different $\mathrm{E}+$ patch sizes: (a) June 21 at 3PM $\left(\lambda_{\mathrm{p}}=0.04\right)$, (b) September 21 at 3PM $\left(\lambda_{\mathrm{p}}=0.04\right)$, (c) June 21 at 3PM $\left(\lambda_{p}=0.44\right)$, and (d) September 21 at 3PM $\left(\lambda_{p}=0.44\right)$

To better compare the influence of patch sizes on the simulation results, Figure 7 shows the Mean Abolute Error (MAE) of the local solar irradiances on the building surfaces for the nine selected days/time. The results show that the selection of the patch sizes has an influence on the simulated results. Figure 7(a) illustrates comparisons between the patch sizes of $1 \mathrm{~m} \times 1 \mathrm{~m}$ and $10 \mathrm{~m} \times 3 \mathrm{~m}$, and Figure $7(\mathrm{~b})$ shows comparisons between the patch sizes of $1 \mathrm{~m} \times 1 \mathrm{~m}$ and $2 \mathrm{~m} \times 1.5 \mathrm{~m}$. While there are differences up to $112 \%$ when the patch size varies from $10 \mathrm{~m} \times 3 \mathrm{~m}$ to $1 \mathrm{~m} \times 1 \mathrm{~m}$, there are no significant differences between the results using patch size of $1 \mathrm{~m} \times 1 \mathrm{~m}$ to $2 \mathrm{~m} \times 1.5 \mathrm{~m}$. It is important to notice that for some days, the large difference originates from the sun exposed patches that have significant difference, e.g. patches 4 and 8 in Figure 6(a). Therefore, to make decision for the selection of patch sizes the results of $10 \mathrm{~m} \times 3 \mathrm{~m}$ and $2 \mathrm{~m} \times 1.5 \mathrm{~m}$ ( or $1 \mathrm{~m} \times 1 \mathrm{~m}$ ), there is a need to use another simulation tool, e.g. Radiance or Daysim, to assess quality of the simulation results. 


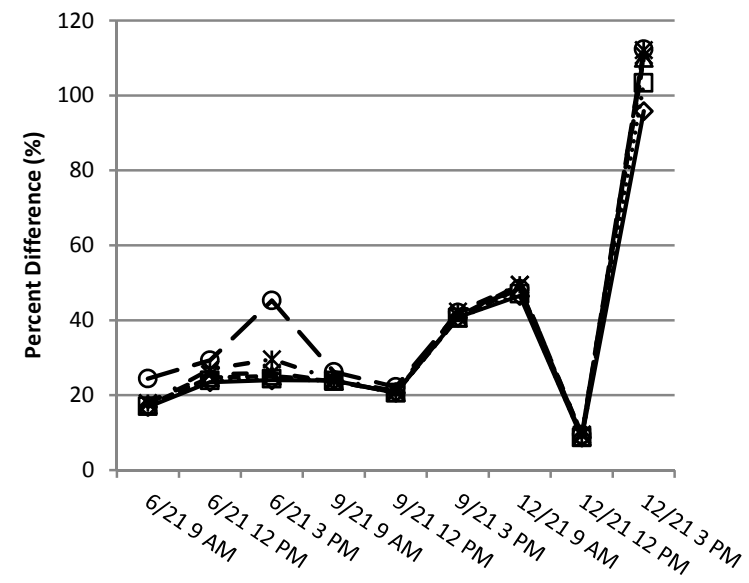

Date Time

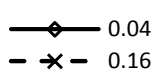

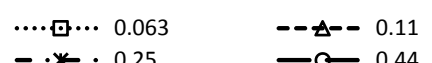

(a)
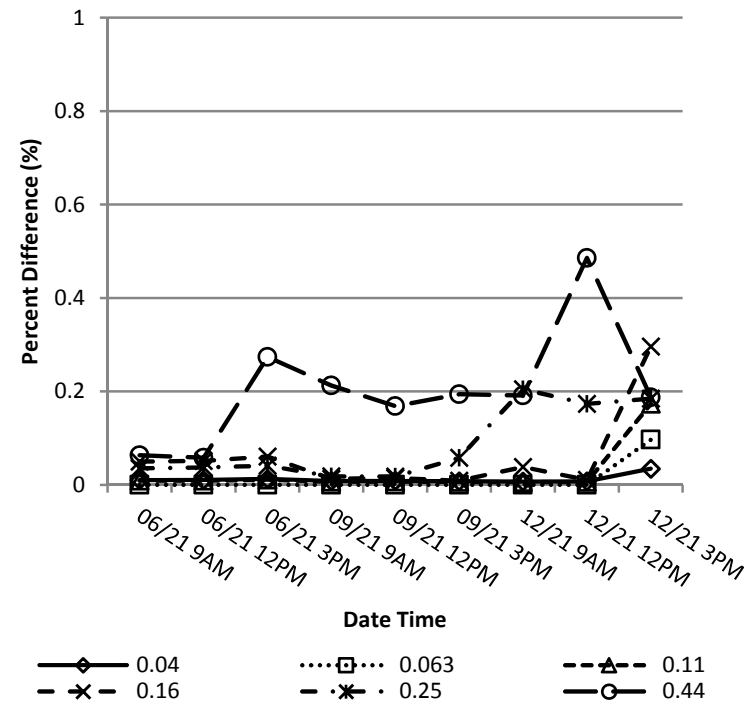

$\cdots \cdots \cdots \cdot 0.063$

- * * 0.25

$-\Delta-0.11$

(b)

Figure 7. Comparison of patch sizes in EnergyPlus: (a) $1 \mathrm{~m} \times 1 \mathrm{~m}$ vs. $10 \mathrm{~m} \times 3 \mathrm{~m}$ and (b) $1 \mathrm{~m} \times 1 \mathrm{~m}$ vs. $2 \mathrm{~m} \times 1.5 \mathrm{~m}$

\subsection{Radiance and Daysim patch sizes}

This section performs a comparison between the values of the solar irradiances with the patch sizes for Radiance and Daysim. Figure 8 shows solar irradiance distributions on the building surfaces for the urban plan area density of 0.44 for the June 21 at $3 \mathrm{PM}$ for patch sizes of $1 \mathrm{~m} \times 1 \mathrm{~m}$ and $2 \mathrm{~m} \times 1.5 \mathrm{~m}$ for Radiance and Daysim tools. The results confirm when the patch sizes are small, e.g. $1 \mathrm{~m} \times 1 \mathrm{~m}$ and $2 \mathrm{~m} \times 1.5 \mathrm{~m}$, the solar irradiances on the building surfaces are similar.

June 21 at $3 P M, \lambda p=0.44$

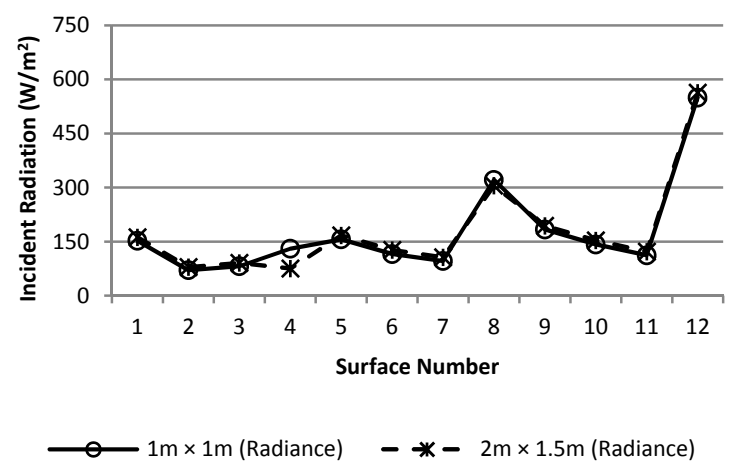

June 21 at 3PM, $\lambda p=0.44$

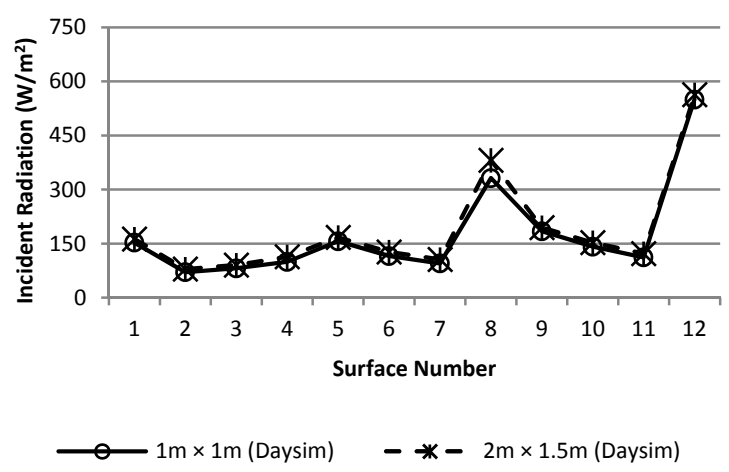

Figure 8. Solar irradiance distribution on the building surfaces for the urban plan area density of 0.44 for the June 21 at 3PM for patch sizes of $1 \mathrm{~m} \times 1 \mathrm{~m}$ and $2 \mathrm{~m} \times 1.5 \mathrm{~m}$ for: (a) Radiance and (b) Daysim

Figure 9 illustrates the percent differences between the solar irradiance values when the patch sizes are $1 \mathrm{~m} \times 1 \mathrm{~m}$ and $2 \mathrm{~m} \times 1.5 \mathrm{~m}$ for Radiance and Daysim. Figure 9(a) confirms that for Radiance, the difference between the calculations 
is less than $11 \%$ at most with the changes in the urban plan area densities. Daysim results illustrated in Figure 9(b) confirm that Radiance and Daysim results are within a similar range.

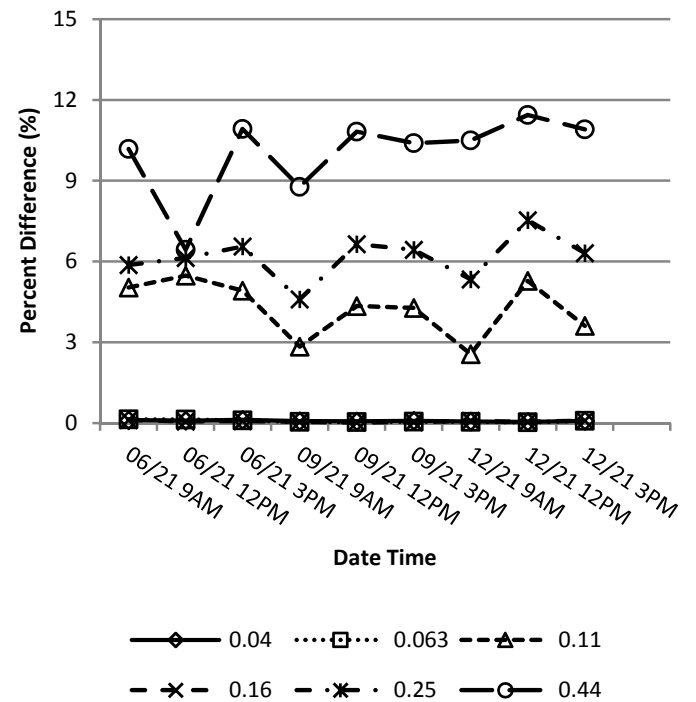

(a)

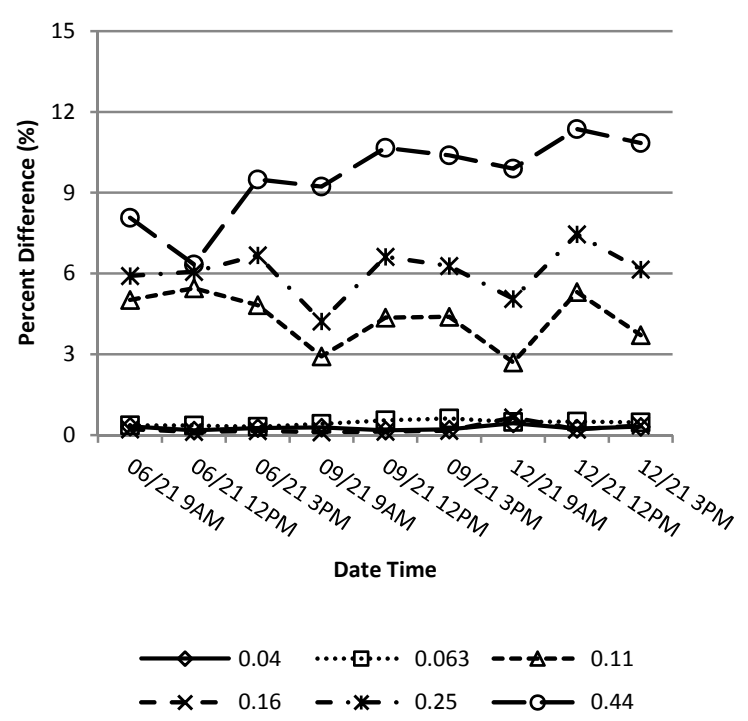

(b)

Figure 9. Comparison of patch sizes between $1 \mathrm{~m} \times 1 \mathrm{~m}$ and $2 \mathrm{~m} \times 1.5 \mathrm{~m}$ patch sizes for the three selected days and hours: (a) Radiance and (b) Daysim

Another important comparison is to confirm how far and close the simulation results from Radiance and Daysim are close to each other. Figure 10 compares the solar irradiances on the building surfaces on June 21 at 3PM for urban plan area density of 0.44 . The results show no significant differences between the Radiance and Daysim simulation results.

June 21 at $3 P M, \lambda p=0.44$

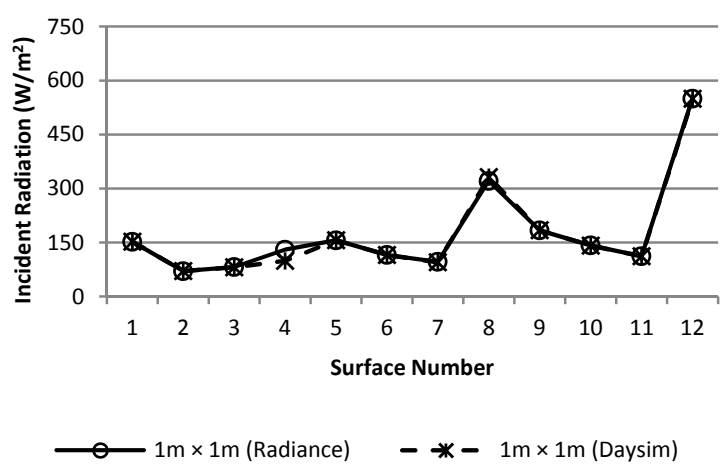

(a)

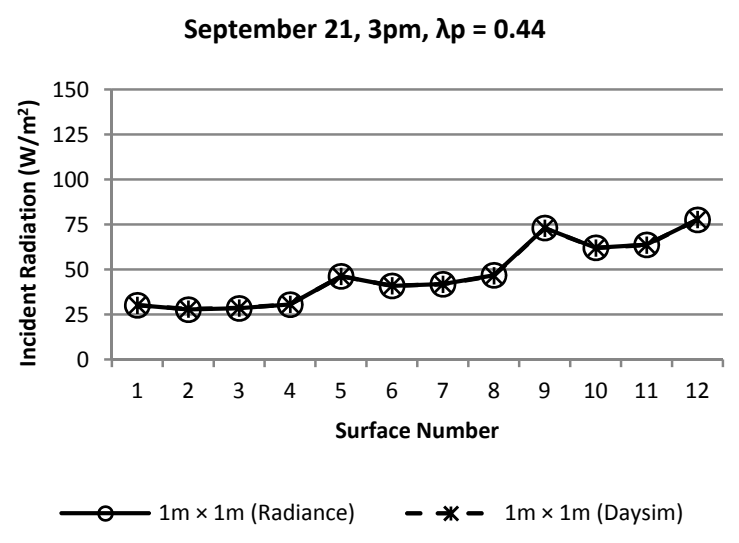

(b)

Figure 10. Comparison of patch sizes between Radiance and Daysim: (a) $1 \mathrm{~m} \times 1 \mathrm{~m}$ and (b) $2 \mathrm{~m} \times 1.5 \mathrm{~m}$ patch sizes

\subsection{Assessment of local solar irradiance distributions for different tools}

An important aspect of this comparison is to lay out the limitation and benefits of using different simulation tools. Therefore, this section aims to compare the local solar irradiances on the building surfaces for three different simulation engines. Figure 11 compares the simulation results for three different simulation engines for patch sizes of $2 \mathrm{~m} \times 1.5 \mathrm{~m}$ and assesses the differences between these simulation results and EnergyPlus when the patch size is 
$10 \mathrm{~m} \times 3 \mathrm{~m}$. To show the differences between the results, Figure 12 depicts the mean averaged error between EnergyPlus and Radiance when the patch sizes are $2 \mathrm{~m} \times 1.5 \mathrm{~m}$ and when the patch sizes are $2 \mathrm{~m} \times 1.5 \mathrm{~m}$ and $10 \mathrm{~m} \times$ $3 \mathrm{~m}$. The results suggest it is better to use large patch sizes, e.g. $10 \mathrm{~m} \times 3 \mathrm{~m}$, rather than the small patch sizes in EnergyPlus. In addition, as Figure 12(b) illustrates, except December 21 at 9AM and urban plan area density of 0.44, the simulated solar irradiances from one per floor simulation of EnergyPlus has a mean averaged error less than $12 \%$. Overall, the results of this parametric study indicates when the sun angle to the building and when the urban neighborhood does not represent a city center neighborhood, the results of one per floor of EnergyPlus provides a reasonably similar simulation results to Radiance and Daysim simulation results.

June 21 at $3 P M, \lambda p=0.44$

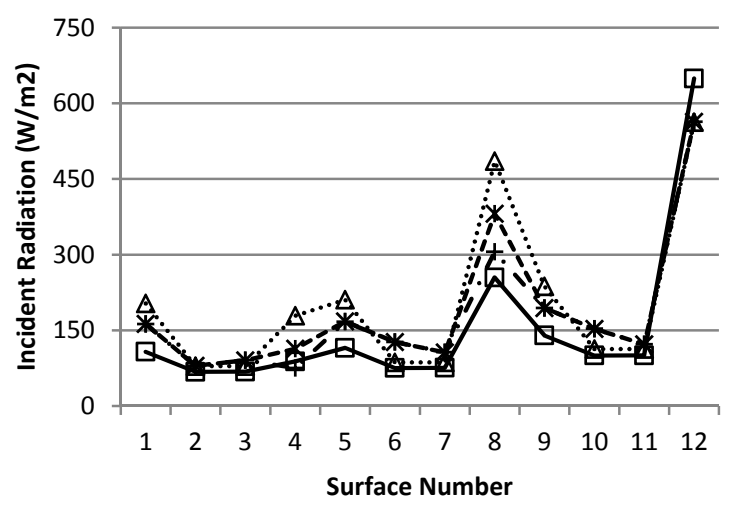

$\begin{array}{ll}\square-2 \mathrm{~m} \times 1.5 \mathrm{~m}(\mathrm{E}+) & \cdots \cdot \Delta \cdot \cdots \cdot 10 \mathrm{~m} \times 3 \mathrm{~m}(\mathrm{E}+) \\ --*--2 \mathrm{~m} \times 1.5 \mathrm{~m}(\text { Daysim) } & -\cdot+\cdot 2 \mathrm{~m} \times 1.5 \mathrm{~m} \text { (Radiance) }\end{array}$

(a)
September 21 at 3PM, $\lambda p=0.44$
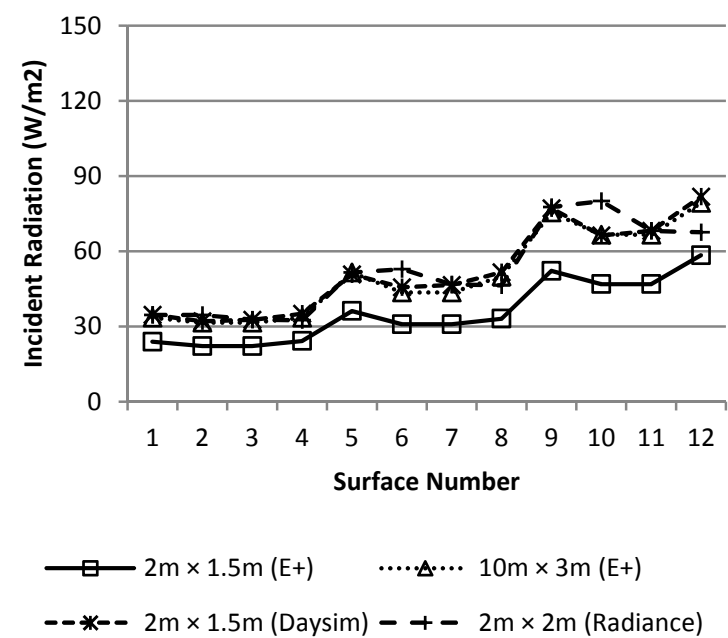

(b)

Figure 11. Comparisons between the simulation results of $E+$ and Radiance for two different patch sizes for June 21 at $3 \mathbf{p m}$

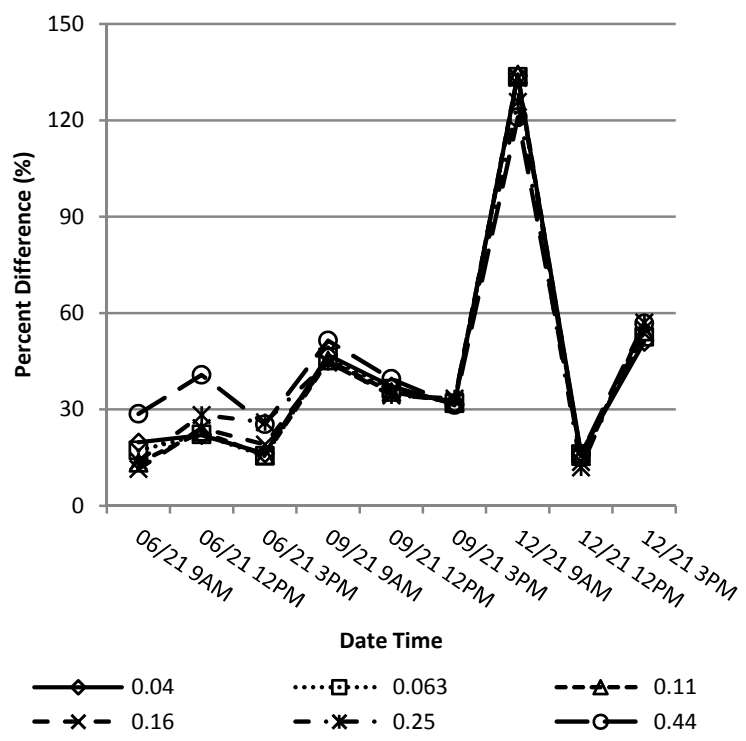

(a)
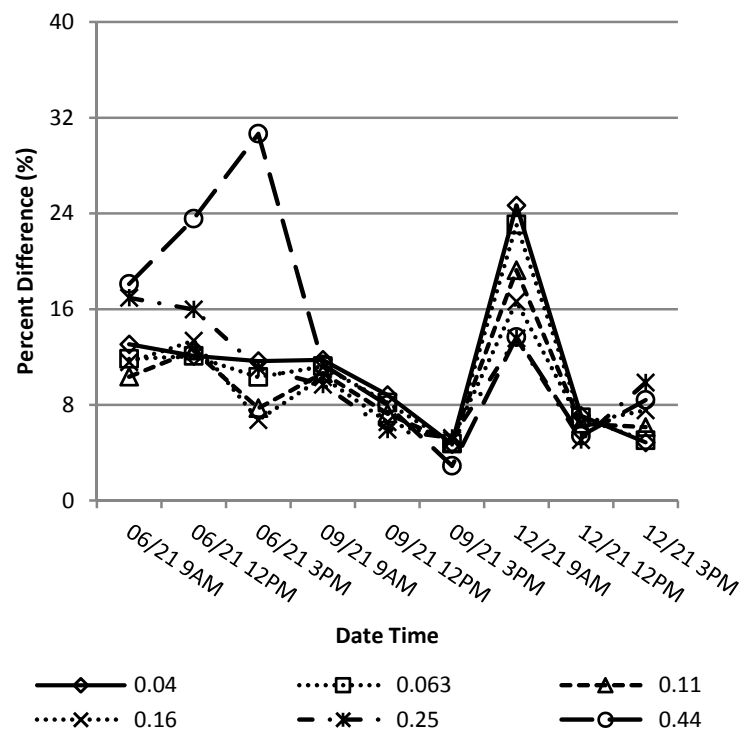

…… 0.063

- - $\Delta--0.11$

- * $0.25 \quad-$ - 0.44

(b)

Figure 12. Comparison of patch sizes between Radiance patch size of $2 \mathrm{~m} \times 1.5 \mathrm{~m}$ and EnergyPlus (a) patch sizes of $2 \mathrm{~m} \times$ $1.5 \mathrm{~m}$ and $(\mathrm{b})$ patch sizes of $10 \mathrm{~m} \times 3 \mathrm{~m}$ 


\subsection{Assessment of averaged solar irradiance distributions for different tools}

This section assesses the variation of global predictions for different simulation tools. For the assessment of the predictions, this study calculates the absolute percent difference between Radiance and Daysim / EnergyPlus results for each calculated surface and each hour. This aggregate parametric study allows to compare aggregate variation of the simulation results for the selected tools. The Radiance $1 \mathrm{~m}$ grid size simulation represents the baseline for comparison of the other simulations due to the robust full ray tracing engine and highest grid resolution. There are 9 hours, $\left(9 \mathrm{am}, 12 \mathrm{pm}\right.$, and $3 \mathrm{pm}$ on June $21^{\text {st }}$, September $21^{\text {st }}$, and December $\left.21^{\text {st }}\right)$, of study and 12 surfaces, so this results in a 108 percent difference for both Daysim and EnergyPlus. The average of these percent differences provides the globally averaged local percent difference between results of the software packages. The absolute value of the percent differences ensures that differentials with positive and negative signs do not enable underestimation of the total percent difference.

Figure 13 shows the total surface averaged radiation for Radiance, Daysim, and EnergyPlus for different urban plan area densities. This study calculates all of the surface radiation values and represents them each simulation in a single diagram as shown in Figure 13. The total incident radiation decreases in two linear patterns, at first a low slope starting at urban plan area density of 0.04 and continues until an urban plan area density of 0.23 , followed by a high slope, starting from urban plan area density of 0.23 to an urban plan area density of 0.44 . The change in slope occurs as the shadows begin to be casted onto the buildings due to the increase in the urban plan area density. In the first low slope region, differences between the models to calculate the sun position, sky distribution, and the ground reflection play a significant role. The interaction of the solar rays and the building configurations provides an inflection point in the results. In the second high slope region, the calculation of shadows and receiving part of the surfaces on the building surfaces affect the calculations.

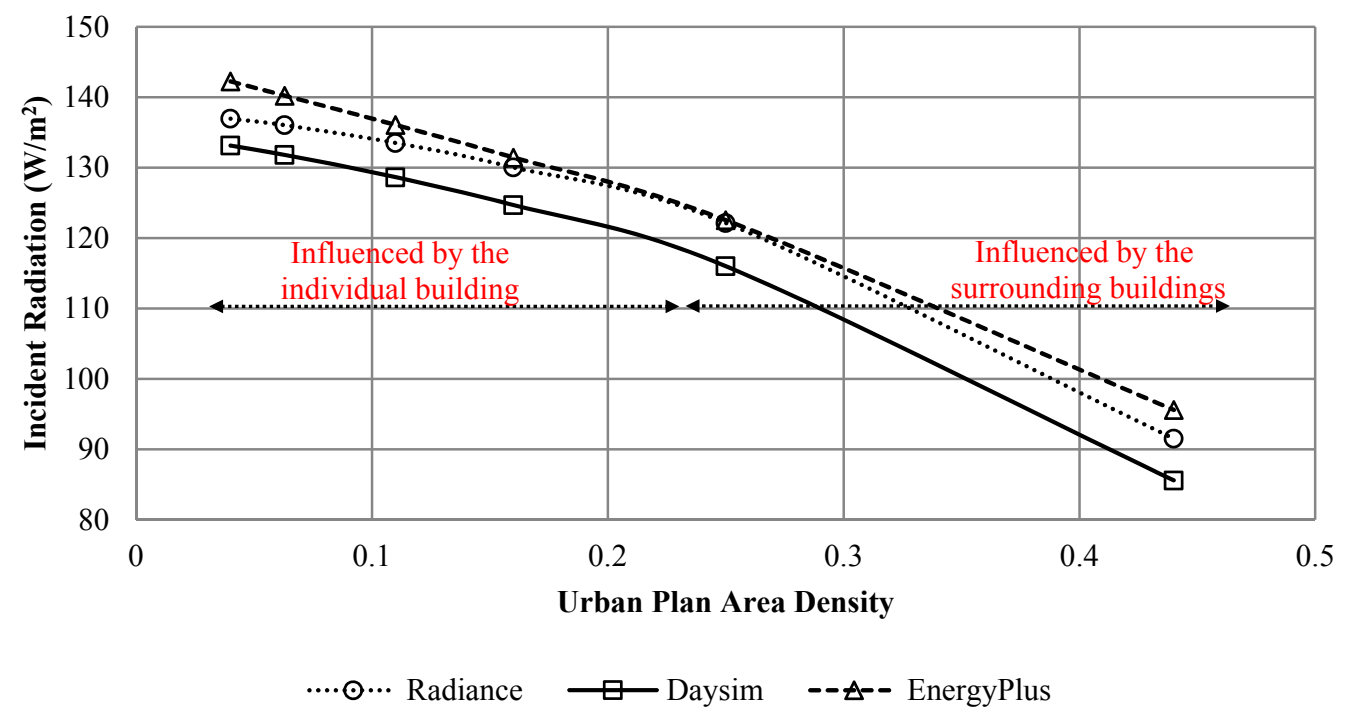

Figure 13. Global solar incident radiation for Radiance, Daysim, and EnergyPlus for different plan area densities

To better quantify the differences between the simulation tools, Figure 14 shows the percent difference between whole building averaged incident radiation for the two sets of simulation results, including EnergyPlus and Daysim, against Radiance simulation results. Since this study totally averages the surface radiation, it is less telling of local discrepancies, as these local errors may cancel each other out on the whole building scale. As it is shown in Figure 13, simulation results for the Daysim and Radiance are parallel to each other with a shift indicating these two tools benefit from similar models. It is also possible to make this conclusin form Figure 14 since the difference between global average Daysim and Radiance shows a linear pattern. Note that Daysim tended to under-predict surface 
radiation and EnergyPlus had a mix of over-prediction and under-prediction, biased slightly towards over prediction. EnergyPlus seems to overestimate radiation compared to Radiance. Daysim consistently underestimates the radiation in this case, and the discrepancy shows consistent growth with density. Overall, the simulation results are very close to each other suggesting for these configuration of urban neighborhoods EnergyPlus, Radiance, and Daysim results within an $8 \%$ range of variations.

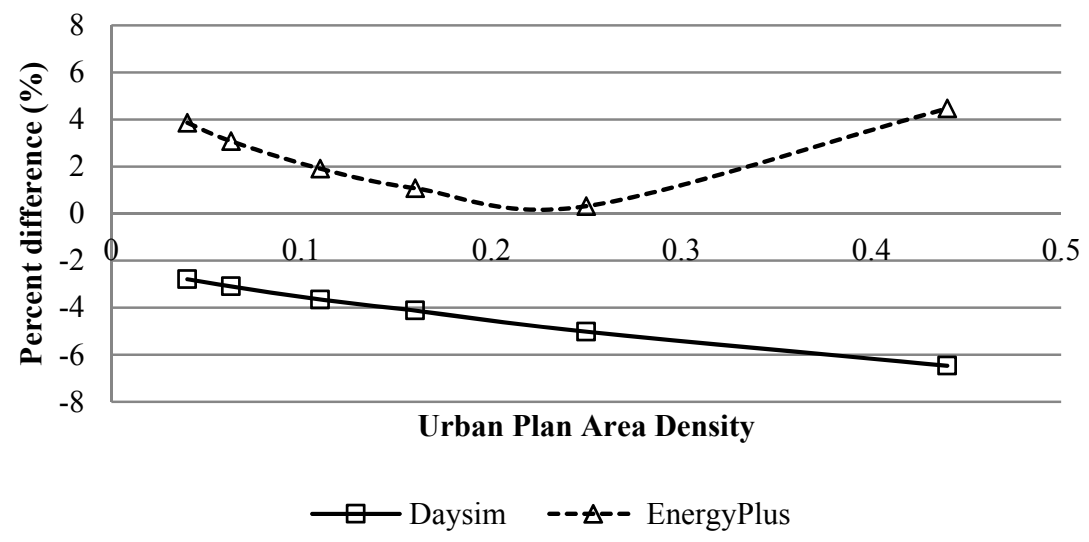

Figure 14. Percent difference of the Daysim and EnergyPlus simulation results from the Radiance simulations

To demostrate the influence of the local distribution of solar irradiance for the two selected grid sizes of $1 \mathrm{~m}$ and $2 \mathrm{~m}$, Figure 15 shows the results in correlation with urban plan area density The methodology here inspects the absolute percent difference at each test point, and averages this, removing the ability for errors to cancel each other out, as is possible when comparing whole building summed radiation as in Figure 14. Figure 2, Figure 4, and Figure 5 illustrate the grid cell sizes of $1 \mathrm{~m}$ and $2 \mathrm{~m}$ for both EnergyPlus and Daysim simulations. For Daysim, the percent difference grows near linearly as urban density increases. EnergyPlus oddly shows a minimum error for the middle densities, which then increases to the maximum error at the highest density. It is worth noting that the highest percent difference seen for Daysim is similar to the minimum percent difference for EnergyPlus. A comparison between the results for $1 \mathrm{~m}$ test points, Figure 15(a), and $2 \mathrm{~m}$ test points, Figure 15(b), show the difference between test points is negligible. Therefore, the $2 \mathrm{~m}$ sized grid cells can accurately predict the solar radiation on the building surfaces. To quantify the differences of total building incident radiation, the $\mathrm{R}^{2}$ values are calculated comparing the various simulations to the Radiance $1 \mathrm{~m}$ grid case. The resulting $\mathrm{R}^{2}$ values are $0.99,0.89,0.90$, and 0.95 for Radiance 2m, Daysim 1 and 2m, and EnergyPlus, respectively. 


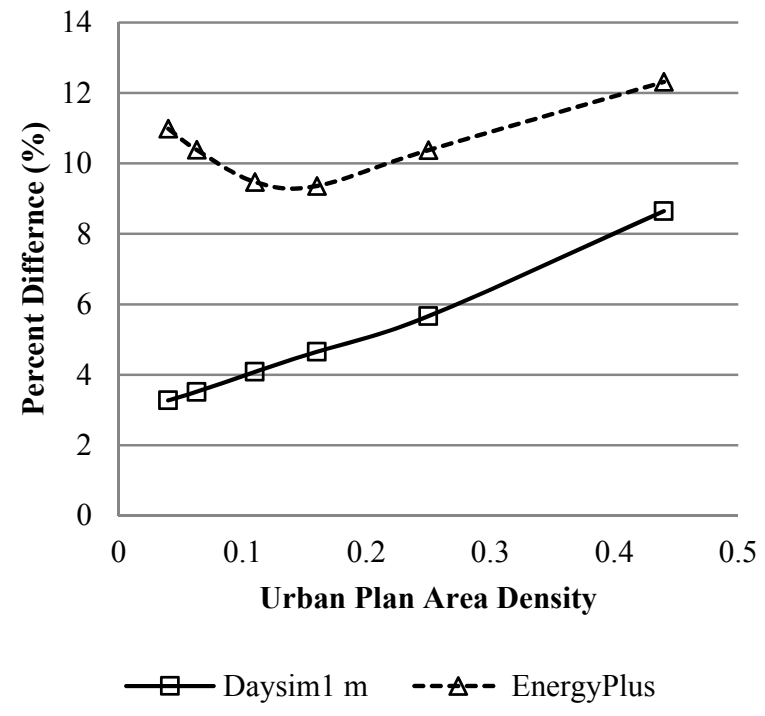

(a)

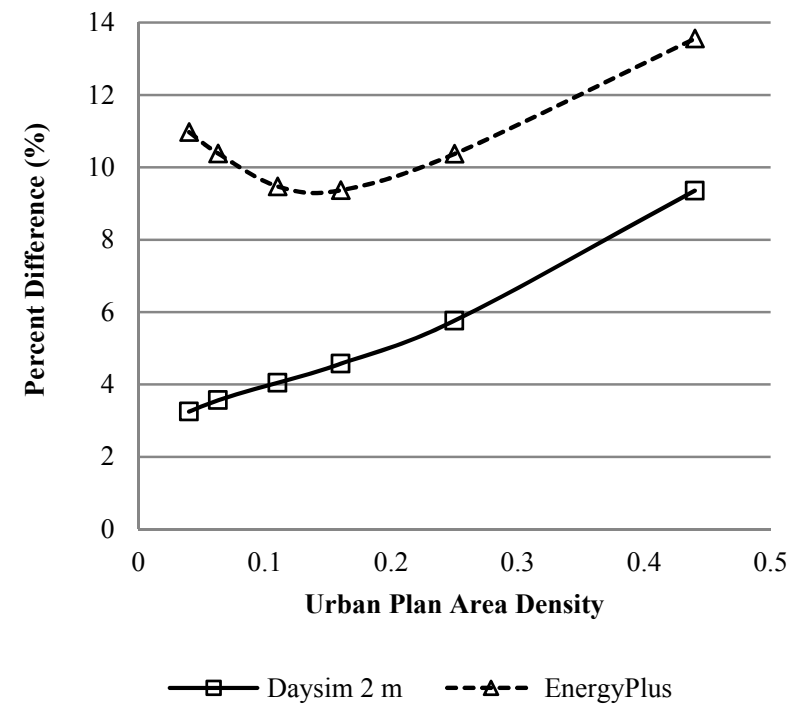

(b)

Figure 15. Percentage of difference between Radiance simulation results and EnergyPlus and Daysim simulation results for grid size of: (a) $1 \mathrm{~m}$ and (b) $2 \mathrm{~m}$

\subsection{Different height variation}

An extension of this study is to consider influence of the surrounding buildings when the height of the surrounding buildings is higher than the building of interest. This extension assesses the influence of the height difference on the simulated solar irradiances on the building surfaces. While the building of interest has a height of "h", the surrounding buildings have a similar height of " $1.5 \mathrm{~h}$ " and " $2 \mathrm{~h}$ ". Figure 16 illustrates the representation of these two difference height variations for the urban plan area density of 0.04 and 0.44 . Consideration of these two urban morphologies allows assessing impacts of the surrounding building heights on the building of interest surface irradiances. Due to reasonable agreement of the one surface per floor compared to the $1 \mathrm{~m} \times 1 \mathrm{~m}$ and $2 \mathrm{~m} \times 1.5 \mathrm{~m}$ patch sizes for the $\mathrm{E}+$ simulations, representation of the surfaces in the $\mathrm{E}+$ simulations use one surface per floor. Radiance and Daysim simulations utilize $2 \mathrm{~m} \times 2 \mathrm{~m}$ patch sizes.

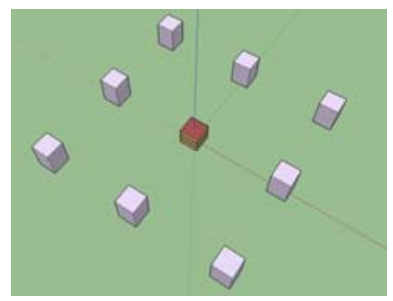

(a)

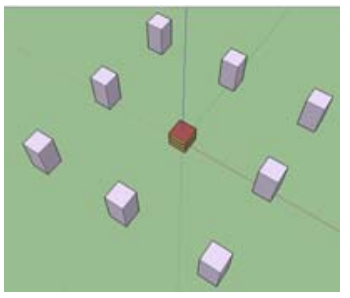

(b)

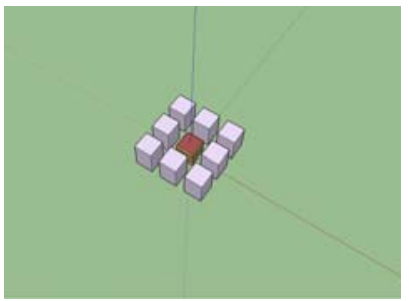

(c)

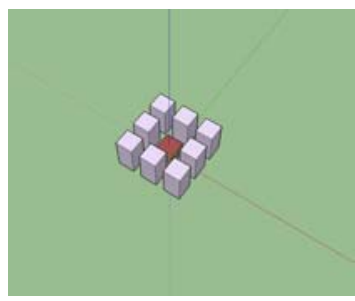

(d)

Figure 16. Height variation in urban plan area density of 0.04 and 0.44 : (a) $1.5 \mathrm{~h}$, (b) $2 \mathrm{~h}$, (c) $1.5 \mathrm{~h}$, and (d) $2 \mathrm{~h}$

Figure 17 shows the distribution of solar irradiances on the building surfaces for two different urban plan area densities and two different days. The distribution of the solar irradiances on the building surfaces for September 21 is similar to the variation of solar irradiances for December 21. However, the magnitudes and distributions for June 21 are different from the other two representative days. Therefore, this study selects June 21 and September 21 to illustrate the variation of solar irradiances on the building surfaces. The results for urban plan area density of 0.04 illustrated in Figure 17(a) and Figure 17(b) indicate that when the buildings are far from each other, the surrounding buildings do not have any influence on the building of interest. On contrary, for urban plan area density of 0.44 
depicted in Figure 17(c) and Figure 17(d) when buildings are within the same height, the buildig of interest is not completely covered by the shadow of the surrounding buildings. However, for height ratio of $1.5 \mathrm{~h}$ and $2 \mathrm{~h}$, the the impact of shadow of the surrounding building on the building of interest decreases. Therefore, the variations and magnitudes of $1.5 \mathrm{~h}$ and $2 \mathrm{~h}$ are within the margin of error and differ from the $1 \mathrm{~h}$.

June 21 at $3 P M, \lambda p=0.04$

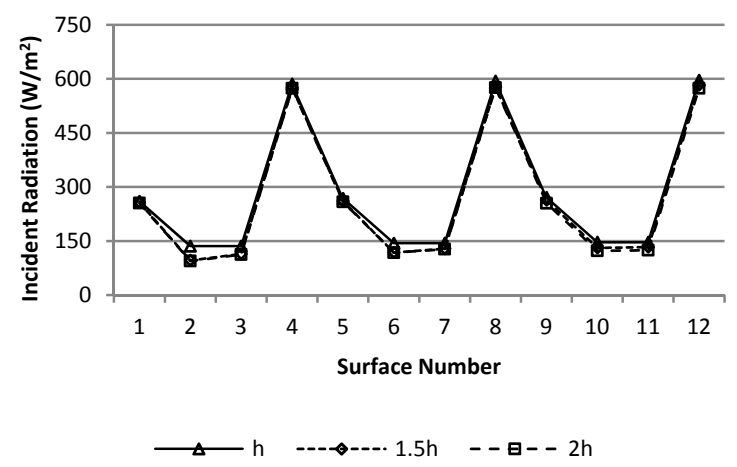

(a)

June 21 at $3 P M, \lambda p=0.44$

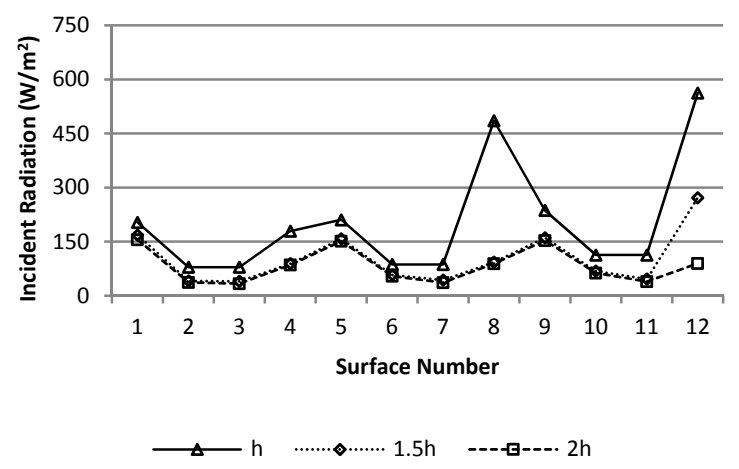

(c)

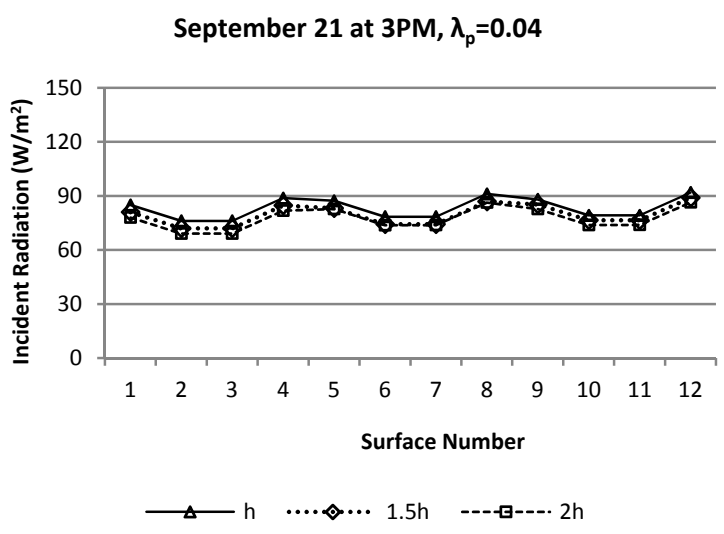

(b)

September 21 at $3 P M, \lambda p=0.44$

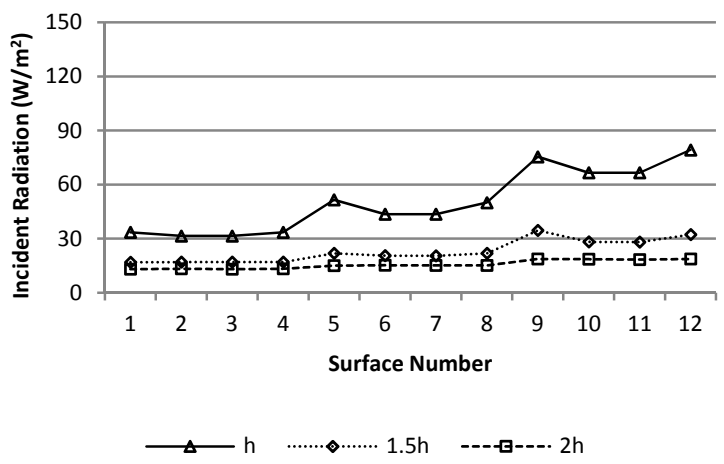

(d)

Figure 17. Solar irradiance distribution on the building surfaces for two different urban plan area densities and two representative time on: (a) June 21 at 3PM $\left(\lambda_{p}=0.04\right)$, (b) September 21 at 3PM $\left(\lambda_{p}=0.04\right)$, (c) June 21 at 3PM ( $\left.\lambda_{p}=0.44\right)$, and (d) September 21 at 3PM $\left(\lambda_{p}=0.44\right)$

The next step of sensitivity analyses assesses the differences between the EnergyPlus simulation results and Radiance as well as Daysim simulation results. Figure 18 illustrates four different cases that compare the EnergyPlus simulation results with the Radiance and Daysim simulation results when the height of the surrounding buildings are 1.5 and 2 times of the building of interest. Figure 18(a) and (b) illustrate differences between Radiance and EnergyPlus when the height of surrounding buildings are 1.5 and 2 times of the building of interest. The results of these two figures indicate that there are differences between the solar irradiance values on the building surfaces specially when the buildings are close to each other, e.g. $\lambda_{p}$ is equal to 0.25 and 0.44 . For the other urban neighborhoods, including neighborhoods with urban plan area densities of 0.04, 0.063, and 0.11, except June 21, the differences are less than 15\%. The results of comparison between Daysim and EnergyPlus in Figure 18(c) and (d) show a similar pattern as the EnergyPlus and Radiance comparion. Overall, the results of this section shows that dense neighborhoods and days when the sun angle to the building is higher than other days, the impact of height becomes more significant. 


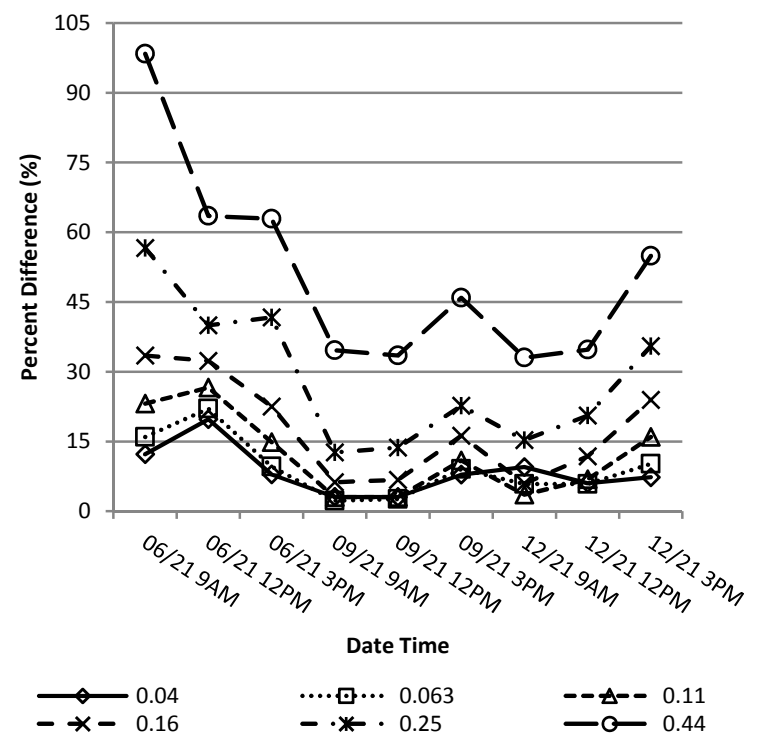

(a)

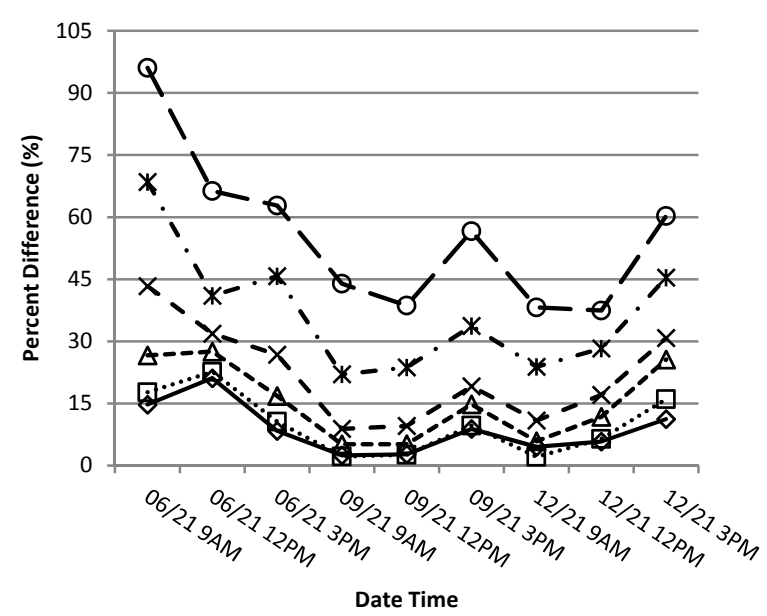

$\sim$
$-x-0.16$

$\begin{array}{ll}\cdots \cdot \bullet \cdot 0.063 \\ -\cdot * \cdot 0 & 0.25\end{array}$

(c)

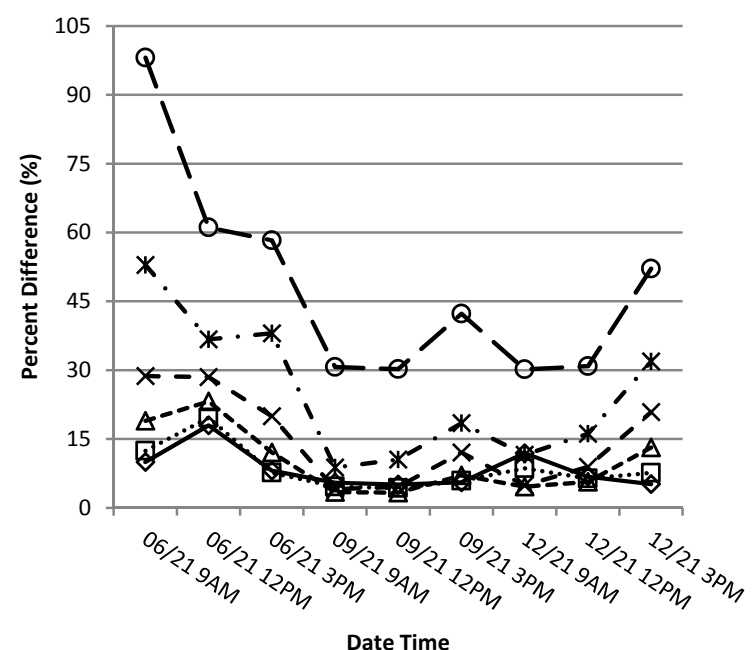

$\longrightarrow$
$-x-0.16$

$\begin{array}{ll}\cdots \cdot \boxminus \cdots & 0.063 \\ \text { 一** } & 0.25\end{array}$

$-\Delta-\Delta 0.11$
$-0-0.44$

(b)

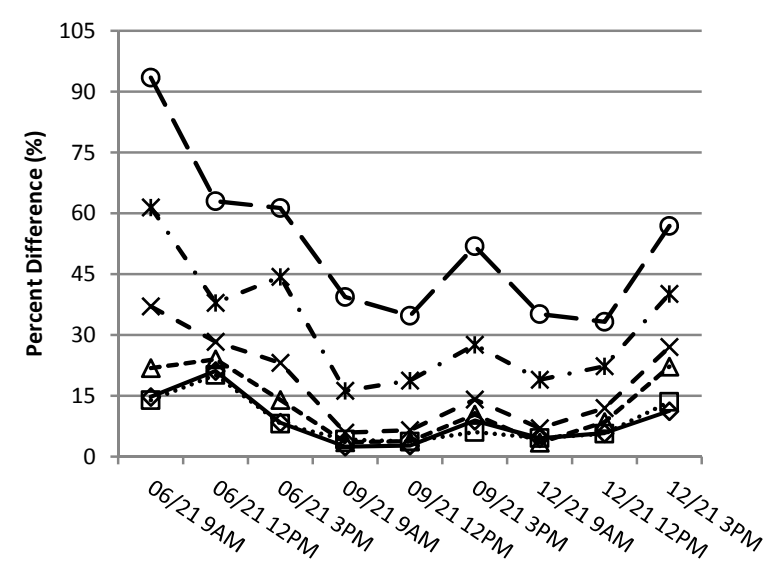

Date Time

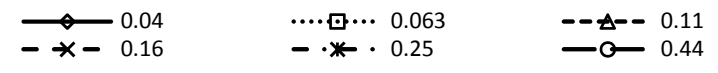

(d)

Figure 18. Averaged percent difference for twelve surfaces between solar irradiance values of (a) Radiance and EnergyPlus for the case of $1.5 \mathrm{~h}$, (b) Radiance and EnergyPlus for the case of $2 \mathrm{~h}$, (c) Daysim and EnergyPlus for the case of 1.5h, and (c) Daysim and EnergyPlus for the case of $2 \mathrm{~h}$

\section{Implementation in CFD}

One of the main boundary conditions in the aiflow simulations is the thermal boundary conditions. Consequently, implementation of the heat fluxes in the CFD simulation requires consideration of different aspects. Table 1 and Table 2 provide a summary of the limitations and benefits of using different solar radiation simulation tools for the outdoor CFD simulations. For example, although researchers usually tend to rely on Radiance and Daysim for ray tracing of outdoor applications, it only provides the solar irrdiance values and do not consider the influence of the building thermal mass. As an alternative, EnergyPlus automatically considers the thermal mass of the building of interest meaning no extra physical model is required for the integration the building surface irradiances as temperature boundary conditions for the implementation in the CFD simulations. 
Table 1. A summary of EnergyPlus, Daysim, and Radiance benefits

\begin{tabular}{|l|l|l|}
\hline \multicolumn{1}{|c|}{ EnergyPlus } & \multicolumn{1}{|c|}{ Daysim } & \multicolumn{1}{|c|}{ Radiance } \\
\hline $\begin{array}{l}\text { 1. Calculate hourly and sub-hourly } \\
\text { outdoor solar radiation for 8760 hours as } \\
\text { well as surface temperature with } \\
\text { consideration of the building thermal } \\
\text { mass. }\end{array}$ & $\begin{array}{l}\text { 1. Provide more accurate solar } \\
\text { irradiance results compared to } \\
\text { EnergyPlus. }\end{array}$ & $\begin{array}{l}\text { 1. Provide more accurate solar irradiance } \\
\text { results compared to EnergyPlus. }\end{array}$ \\
$\begin{array}{l}\text { 2. Design to calculate local heat fluxes } \\
\text { per surface depending on the mesh } \\
\text { Radiance and Daysim. }\end{array}$ & $\begin{array}{l}\text { 3. Denign to calculate local heat fluxes per } \\
\text { surface depending on the mesh generation. } \\
\text { for 8760 hours. }\end{array}$ \\
\hline
\end{tabular}

Table 2. A summary of EnergyPlus, Daysim, and Radiance limitations

\begin{tabular}{|c|c|c|}
\hline EnergyPlus & Daysim & Radiance \\
\hline $\begin{array}{l}\text { 1. Overestimate solar irradiance for } \\
\text { some neighborhood morphologies. } \\
\text { 2. Provide averaged surface heat flux } \\
\text { and temperature readings for each } \\
\text { surface. This may render the tool unable } \\
\text { to consider combination of shaded and } \\
\text { unshaded areas. } \\
\text { EnergyPlus overestimate the irradiance } \\
\text { values and do not offer flexibility for the } \\
\text { number of surface refinements. }\end{array}$ & $\begin{array}{l}\text { 1. Require consideration of a method to } \\
\text { include the thermal mass of the } \\
\text { building. } \\
\text { 2. Take longer to perform similar } \\
\text { simulations compared to EnergyPlus } \\
\text { (Daysim requires hours of simulations } \\
\text { compared to minutes of simulation for } \\
\text { E+). }\end{array}$ & $\begin{array}{l}\text { 1. Require consideration of a method to } \\
\text { include the thermal mass of the building. } \\
\text { 2. Provide a snapshot for the simulation } \\
\text { results although new methods such as } 3 \\
\text { phase or } 5 \text { phase methods can provide } \\
\text { rapid hourly simulations within a minute. }\end{array}$ \\
\hline
\end{tabular}

This section considers three different sets of thermal boundary conditions for the outdoor surface thermal values: (1) $\mathrm{E}+$ simulated results, (2) Daysim simulated results, and (3) a $30^{\circ} \mathrm{C}$ fixed building surface temperature for two different urban plan area densities of 0.04 and 0.44 . Heat fluxes for the boundary condition of CFD surfaces, this study uses June 21 at 3PM. Consideration of these different thermal conditions allow to assess impacts of the surface thermal dissipation on the air velocity and temperature around the buildings located in the urban neighborhoods.

Figure 19 (a) and (b) depict the configuration of mesh for the plan area densities of 0.44 and 0.04 with the distribution of air temperatures. This mesh is generated with the use of SnappyHexMesh enabling automated mesh generations, and consisted of about 4 million cells. The study uses the potentialFoam solver for flow initialization, and the buoyantBoussinesqSimpleFoam solver for calculating the coupled temperature and velocity fields. The solution for one snapshot in time converged to $10^{-5}$ residuals for all variables except pressure that uses $10^{-4}$ in about five hours running on eight Intel Xeon 3.0 GHz processor cores. Figure 19 (c) and (d) illustrate the simulated surface temperatures for outdoor OpenFOAM CFD simulations. The results of these figures show that close to the buildings the influence of the surface temperatures are siginificant. The dissipated heat flux from the building surfaces for the surrounding buildings is higher than the dissipated heat for the buildings located in the middle row due to the shade from the surrounding buildings. The corresponding airflow for this simulation is a function of the surface temperature boundary conditions and wind sheltering effect. 


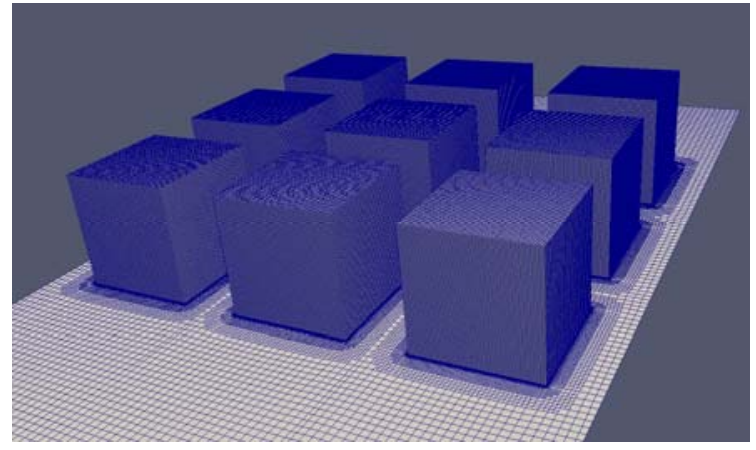

(a)

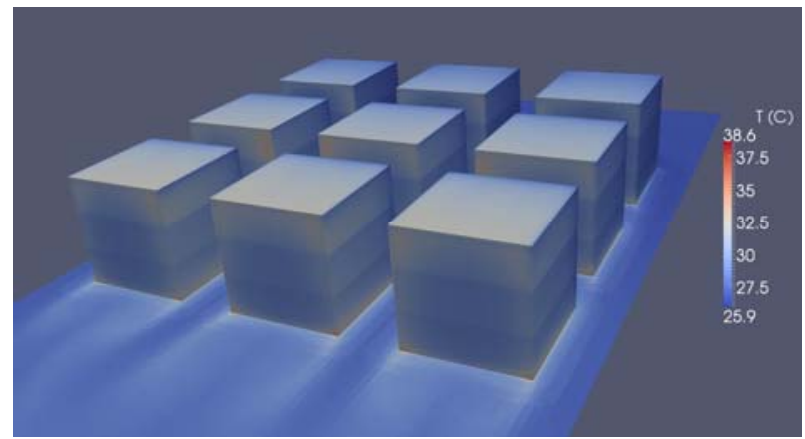

(c)

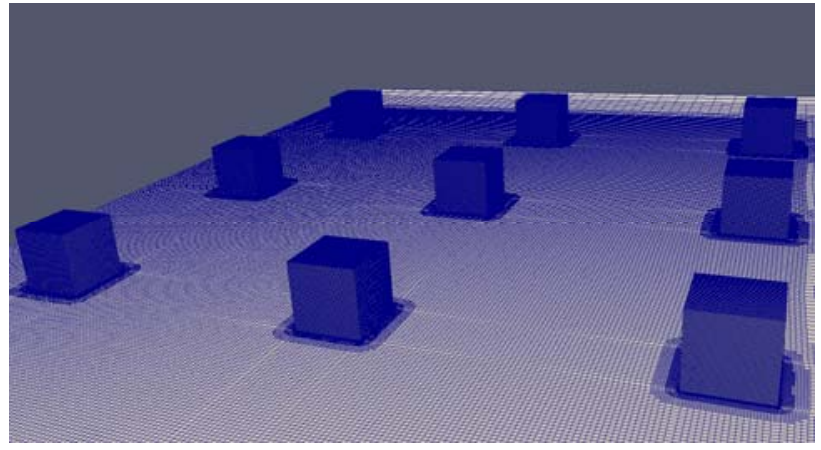

(b)

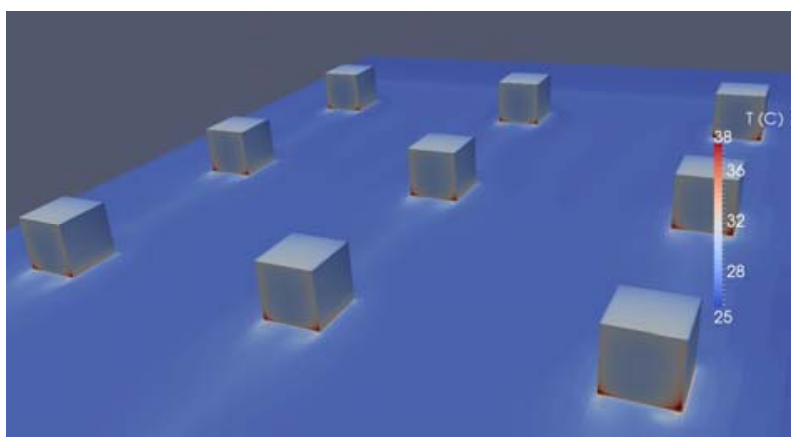

(d)

Figure 19. Mesh distribution for (a) $\lambda p=0.44$ and (b) $\lambda p=0.04$; surface temperatures representing the boundary conditions in the CFD simulations at 3:00 pm local time, June 21 for the plan area densities of (c) 0.44 and (d) 0.04

Figure 20 depict temperature profiles for $1 \mathrm{~m}$ from the windward and leeward walls of the center building for two different urban plan area densities of 0.04 and 0.44 . Implementation of three surface thermal boundary conditions indicate that the surface temperature values have direct impact on the temperature profiles. Overall, difference between the temperature values from $\mathrm{E}+$ and Daysim surface heat fluxes is less than $5 \%$, indicating a good agreement with using different values from the simulated results. The results from the fixed surface temperature boundary condition show that there are discrepancies between the temperature profiles especially in the proximity of the building. When the height reaches to the freestream air the temperature values are identical. The air temperature differences are more significant for the leeward walls and the influence of the building height is very clear. There is a very clear jump in the temperature values before and after $10 \mathrm{~m}$. Figure 20(a) shows the windward temperature profile for the urban plan area density of 0.04 , illustrating very negligible difference between the air temperature values from the $\mathrm{E}+$ and Daysim surface boundary condition setup. For most of the temperature profile, the fixed temperature surface thermal boundary condition is within $0.5 \mathrm{C}$. Figure $20(\mathrm{~b})$ depicts the temperature profile for the leeward of the case with urban plan area density of 0.44 and clearly shows the influence of the building height. The temperature profile for the urban plan area density of 0.44 for the windward wall illustrated in Figure 20 (c) indicates the complex air flow around the buildings located in a dense urban neighborhoods. The most difference between the temperature profiles occur for the leeward of the urban plan area density of 0.44 depicted in Figure 20(d). 


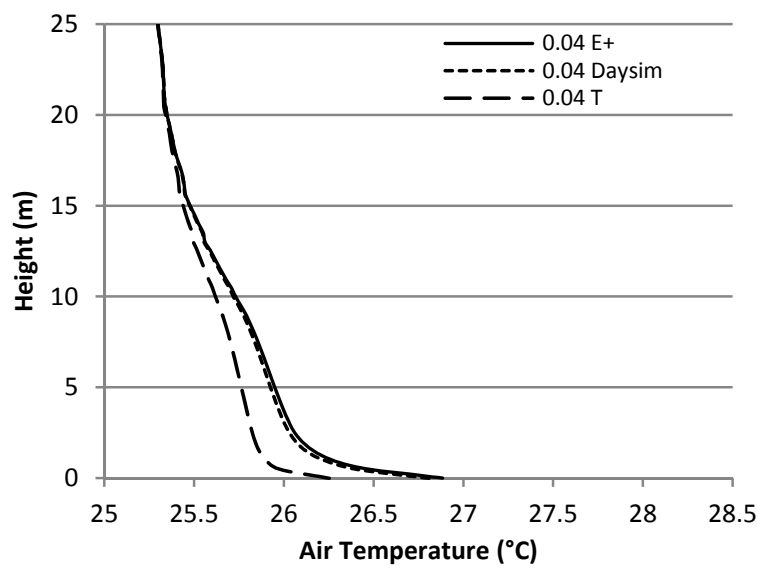

(a)

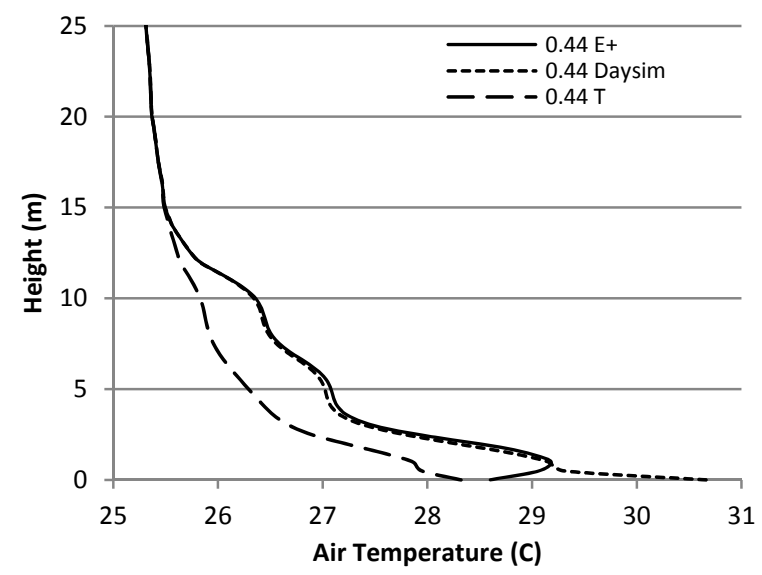

(c)

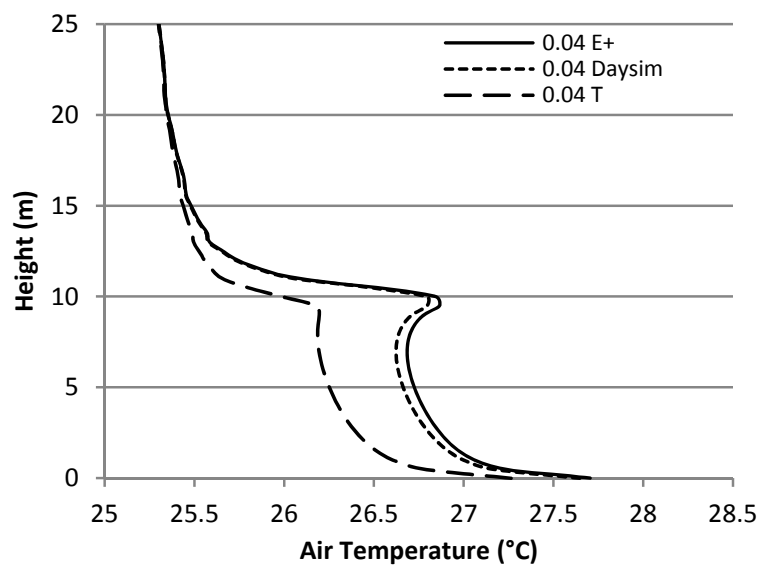

(b)

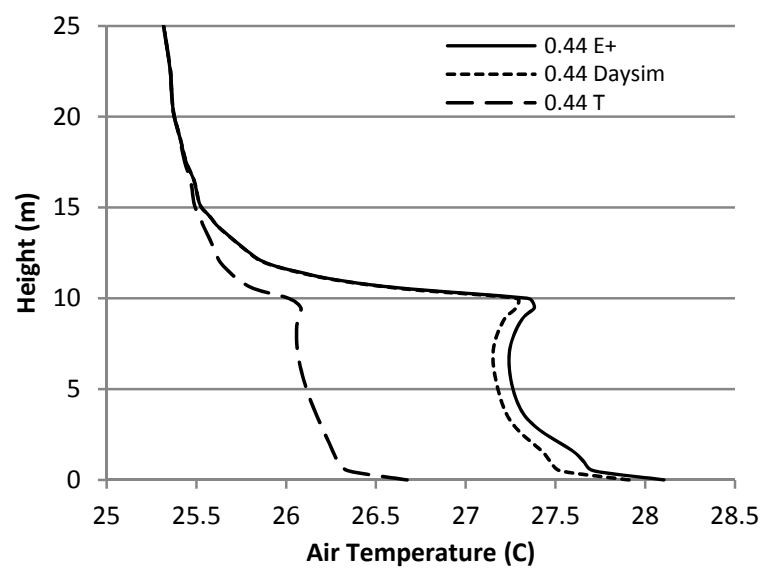

(d)

Figure 20. Temperature profiles as a function of height $1 \mathrm{~m}$ from: (a) windward wall $\lambda p=0.04$, (b) leeward wall $\lambda p=0.04$, (c) windward wall $\lambda p=0.44$, (d) leeward windward wall $\lambda p=0.44$. Figure (c) uses $31 \mathrm{C}$ instead of $28.5 \mathrm{C}$ as the $\mathrm{x}$ maximum axis.

Figure 21(a) and (b) show the temperature profiles for $1 \mathrm{~m}$ from the lateral walls. Compared to the windward and leeward walls, the discrepancies between the temperature profiles for the lateral walls are less significant. Figure 21(a) show within the thermal boundary layer, the temperature profile from the fixed surface temperature boundary conditions, are within on average $1 \mathrm{C}$ temperature difference compared to the temperature profiles from the $\mathrm{E}+$ and Daysim surface boundary conditions. Figure 21(b) also indicate the air temperature difference between the three different surface thermal boundary conditions are not significant. 

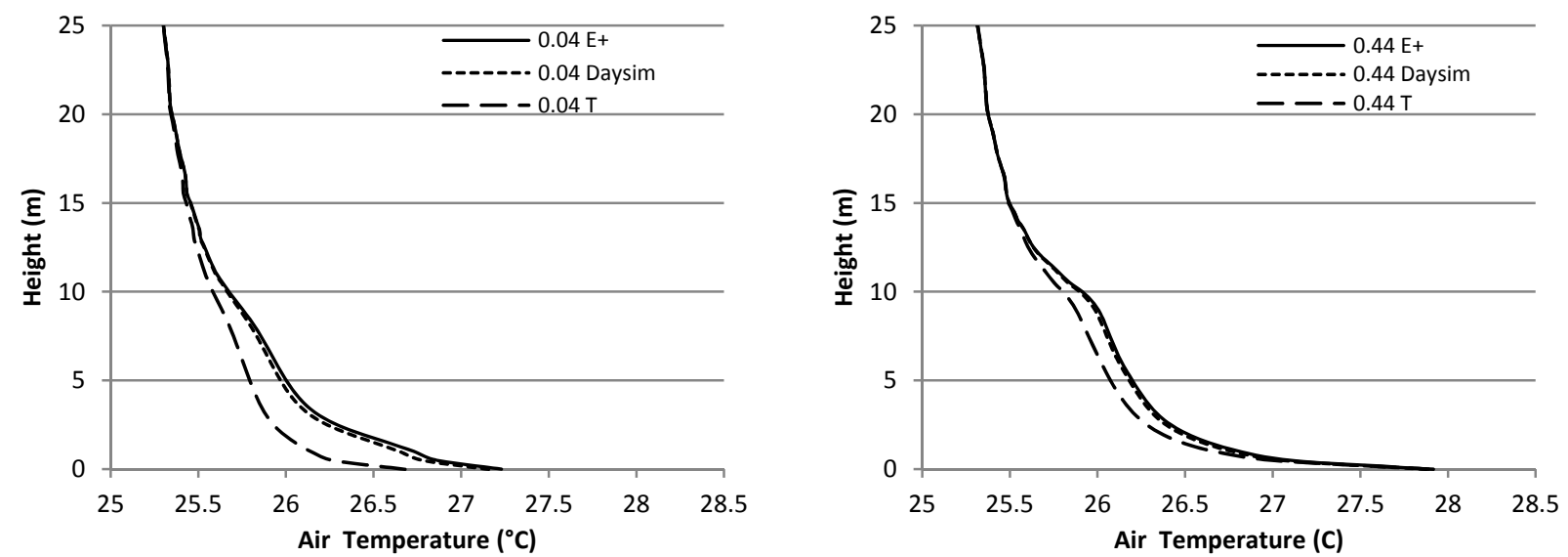

Figure 21. Temperature profiles as a function of height $1 \mathrm{~m}$ from the lateral walls when: (a) $\lambda p=0.04$ and (b) $\lambda p=0.44$

The results of the velocity profiles at different locations $1 \mathrm{~m}$ from the windward and leeward wall illustrated in Figure 22 indicate that the air velocity does not depend strongly to the surface wall thermal boundary conditions. Velocity profiles simulated from the three surface thermal boundary conditions are within the same range.

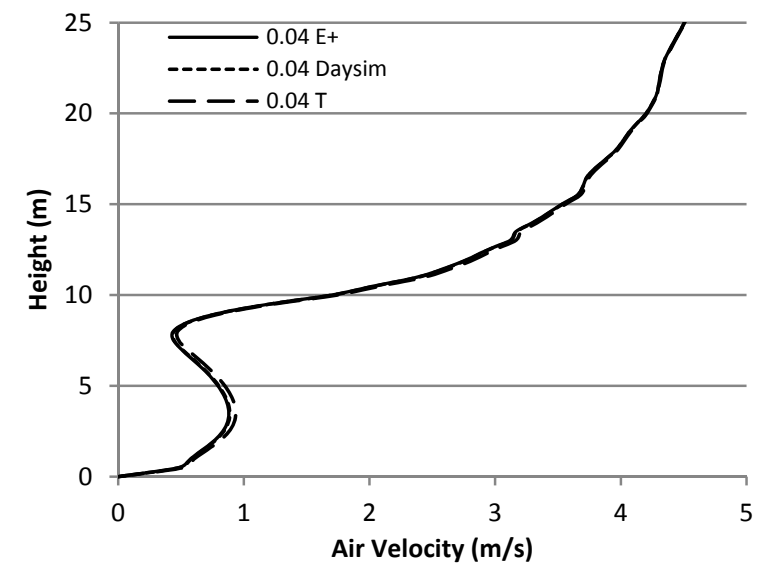

(a)

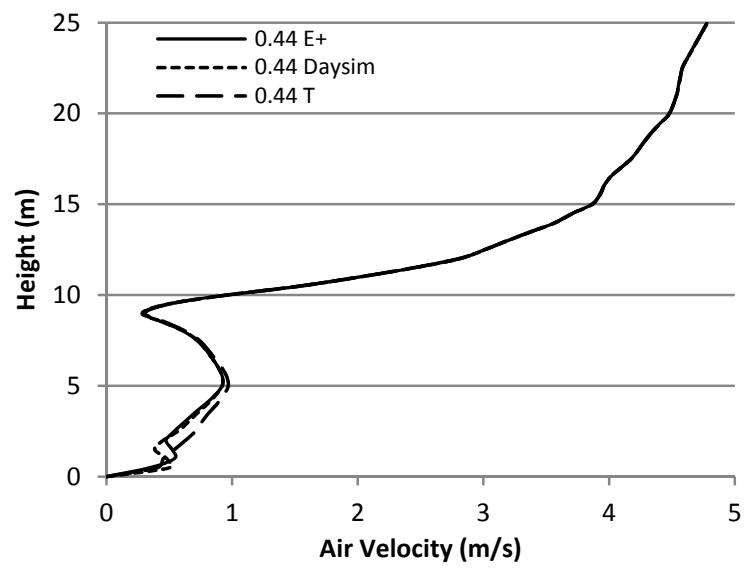

(b)

Figure 22. Velocity profiles as a function of height $1 \mathrm{~m}$ from: (a) windward wall $\lambda p=0.04$ and (b) windward wall $\lambda p=0.44$

Figure 23 illustrates the airflow simulation results for the urban plan area density of $\lambda p=0.44$, indicating the recirculation eddies between the buildings. The temperature profiles illustrated in Figure 20(b) and (d) as well as the velocity profile depicted in Figure 22(b) confirms the existence of these recirculation eddies. 


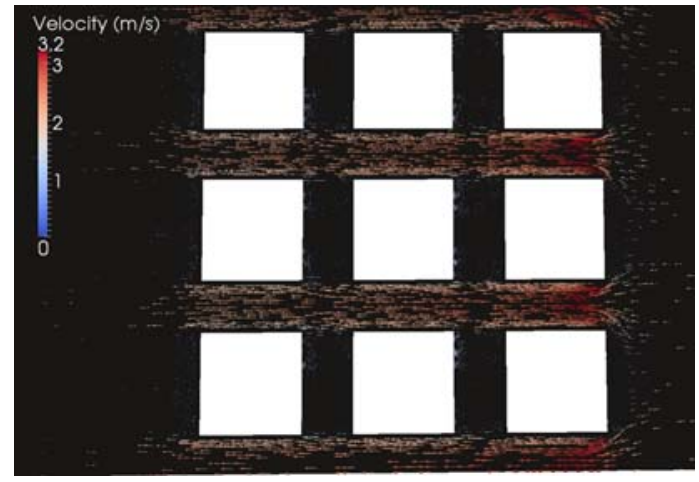

(a)

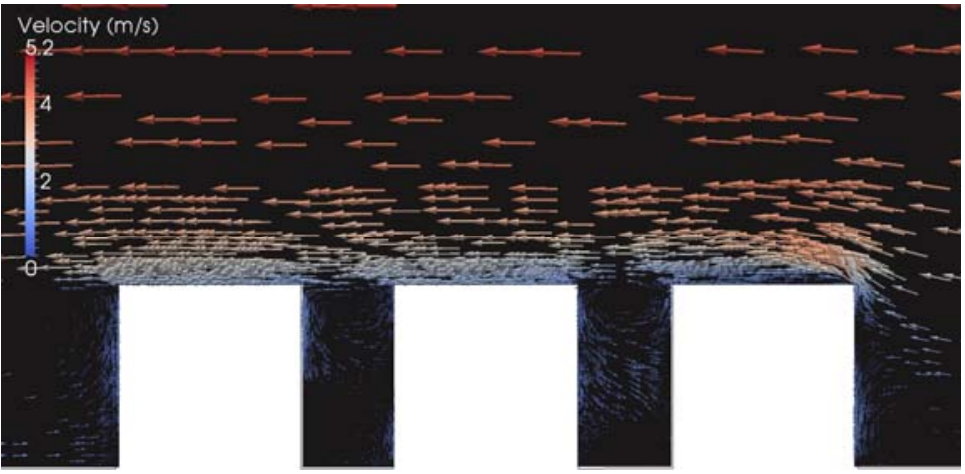

(b)

Figure 23. Airflow around the buildings for the case of $\lambda p=0.44$ : (a) Top view showing the velocity varies between 0 to 3.2 $\mathrm{m} / \mathrm{s}$ and (b) Centerline vertical view indicating the velocity varies between 0 to $5.2 \mathrm{~m} / \mathrm{s}$

Overall, the results of implementating different surface boundary conditions indicate that the surface thermal boundary conditions have effect on the air temperature especially on the leeward surfaces and the windward surfaces more than the velocity profiles. The significane of the thermal boundary conditions on the lateral surfaces is lower than the leeward and windward surfaces. These results have implications on the calculation of the significance of the natural convection that is function of temperature difference $(\Delta T)$ and the forced convection which is a function of velocity (V). Therefore, the results of this study have direct and indirect impact on the calculation of the outdoor conditions for the buildings located in the built environment.

\section{Broader Implications}

The results of this study offer insight on the use of simulation engines, including EnergyPlus, Radiance, and Daysim, to calculate building surface heat fluxes for implementation in the outdoor airflow CFD simulations. The current study uses urban plan area density as a proxy to consider the influence of urbanization in cities. The results of this study have direct and indirect implications in the design of sustainable urban neighborhoods. For example, a potential implication of this work is to calculate the local temperatures around the buildings that have impacts on the efficiency of cooling systems for buildings. Changes in the heat fluxes on building surfaces have direct impact on the heat transfer processes close to the building surface where incoming air temperatures affect the efficiency of building cooling systems (Gracik et al., 2015). Therefore, these local temperatures not only affect the efficiency of mechanical cooling equipment, but also the building energy use.

The results of this study also has direct implications on the prediction of urban ventilation around buildings built in the urban areas, mitigation strategies in the change of materials (Mirzaei, 2015), outdoor thermal comfort of pedestrians (Mirzaei \& Haghighat, 2010) as well as dispersion of air pollutants in the built environment that has direct impacts on the health of people who reside in the built environment. These mitigation strategies also allow reduction of the exterior surface temperature. For example, changes in the material replacement by the means of outdoor CFD simulations as one of the measures to reduce the surface temperature in the built environment of up to $6.5^{\circ} \mathrm{C}$ (Dimoudi et al., 2014). The other implication of calculation of surface temperature and heat fluxes supports installation of Photovoltaic (PV) solar panels that require consideration of the solar irradiance distribution on the building surfaces (Kodysh et al., 2013; Moghadam \& Deymeh, 2015). In addition, another implication for the results of this study is to consider adding the exterior surface heat fluxes on the building surfaces for the mapping tools such as Geographic Information Systems (GIS) based tools that are considered for the assessment of energy consumptions in the built environment (Karan et al., 2015). Overall, the results of this study support a wide range of application. 
In the assessment of the urban neighborhood height variation, this study considered parameter " $h$ " as the primary building height and varied the surrounding building heights. Three different surrounding heights selected in this study were surrounding building with heights of $\mathrm{h}, 1.5 \mathrm{~h}$, and $2 \mathrm{~h}$. One possibility for the future studies is to develop a non-dimensional parameter similar to the urban plan area density for the height variation that could consider the impacts of the building heights, sun angle, and position of the building surfaces relative to the sun.

Calcultion of more accurate total balance of the heat transfer processes close to the wall in the EnergyPlus may lead to more precise surface heat fluxes. For this initial study, the EnergyPlus simulations are run independent of CFD. EnergyPlus simulations make use of CTFs for conduction through the wall, and the DOE-2 convection algorithm to resolve the heat fluxes and wall surfaces temperatures of buildings. The exterior surface heat fluxes are copied from the EnergyPlus output into OpenFOAM boundary condition files. Currently OpenFOAM does not feature the capability to apply both a surface temperature and a convection coefficient to a boundary condition without modification, and doing so would create an overly constrained boundary condition. Future studies may consider this however to create additional congruency between the CFD and energy simulations. Future studies should aim to establish two-way coupling between the simulations, using EnergyPlus to supply temperature distributions, and OpenFOAM to calculate the convection coefficient from the temperature gradient resulting from the CFD simulation; which would be sent back to EnergyPlus to recalculate the temperature distribution, and so on. At this time, radiative heat transfer between buildings is limited to the EnergyPlus simulations. CFD simulations are run at steady state, providing snapshots in time from hourly EnergyPlus results.

Overall, the selected morphology parameters in this study represent simple urban neighborhoods that have implication for urban neighborhoods with similar heights, such as neighborhoods located in Washington, DC. Therefore, the effectiveness of the reviewed tools is based on the considered urban morpholgy parameters, including urban plan area density and buildings with similar heights. Radiance is a pure ray tracer, so simulation time will be proportional to the number of rays it shoots while in EnergyPlus, analytical calculations and a small amount of ray tracing and the time required for the simulations is proportional to the number of surfaces in the model. The main reason to consider the reviewed configuration of urban neighborhoods is to consider urban density as a nondimensional variable in order to enable the urban planners and other studies to replicate the results of the simulations and compare the results. The urban density is parameter that was extensively used for the urban canyon and outdoor CFD studies to provide replicable results for convective heat transfer, temperature validation, velocity validation. One of the setbacks is to consider complex geometry in the existing Radiance and Daysim studies is the inability to replicate the results. Overall, this study provides a measure (urban density) and replicable geometry as a reference for future studies.

\section{Conclusions}

This paper assessed limitations and benefits of three simulation tools (Radiance, Daysim, and EnergyPlus) used to simulate the solar irradiance on building surfaces. These incidental radiative fluxes represent boundary conditions for the outdoor airflow simulations of buildings located in an urban neighborhood. The focus is on the quantification of tradeoffs between the modeling assumptions and quality of the simulations, enabling a parametric analysis study. This focus allows assessing differences between the simulation results with different simulation surface representations and addressing limitations and benefits of using different tools. Specifically, this study used three different grid cells sizes, $1 \mathrm{~m} \times 1 \mathrm{~m}, 2 \mathrm{~m} \times 1.5 \mathrm{~m}$, and $10 \mathrm{~m} \times 3 \mathrm{~m}$, for the building surfaces to assess the influence of the number of grid points in the solar radiation simulations for six different urban plan area densities. These urban plan area densities represents different urban neighborhoods, ranging from a neighborhood located in a rural area to a city center neighborhood. The results of this comparison between the solar radiation simulation results revealed that the local performance of Daysim and EnergyPlus simulations is similar. Radiance simulation results that use the most complete set of energy balance equations represented a reference value for the accuracy assessment of simulation results obtained with the other two simulation tools. 
For the local solar irradiances, the EnergyPlus simulation results with patch sizes of $1 \mathrm{~m} \times 1 \mathrm{~m}$ and $2 \mathrm{~m} \times 1.5 \mathrm{~m}$ showed similar patterns for different urban plan area densities and days. Similarly, Radiance and Daysim results are similar for the two selected test points. However, the EnergyPlus simulation results with $10 \mathrm{~m} \times 3 \mathrm{~m}$ showed a different pattern compared to $1 \mathrm{~m} \times 1 \mathrm{~m}$ and $2 \mathrm{~m} \times 1.5 \mathrm{~m}$. Therefore, a follow up comparison between different simulation tools indicate except when the sun angle to the building is low and the urban plan area density is not 0.44 , the EnergyPlus results with patch sizes of $10 \mathrm{~m} \times 3 \mathrm{~m}$ are within $12 \%$ of the Radiance and Daysim results. Therefore, there is no need to consider detailed patch sizes in EnergyPlus in order to speed up the simulation results.

For the global accuracy assessment, EnergyPlus case has slightly closer results to the Radiance case compared to the Daysim case. The total solar incident irradiance showed two different patterns. Specifically, starting at an urban plan area density of 0.04 to an urban plan area density of 0.23 and from urban plan area density of 0.23 to an urban plan area density of 0.44 , two different patterns emerged. The change in slope occurs due to the appearance of shadows on the buildings when the urban plan area density increases. Differences between the calculations of the sun position, sky distribution, and the ground reflection, as well as calculations of the shadows and receiving part of the surfaces are the major reasons for these two different patterns. This study quantified the differences of total building incident radiation from the Radiance, Daysim, and EnergyPlus for different grid sizes. $\mathrm{R}^{2}$ specifies the deviation of the Radiance results with grid size of $1 \mathrm{~m}$ with the Daysim when the grid sizes are $1 \mathrm{~m}$ and $2 \mathrm{~m}$ and the EnergyPlus results. The resulting $\mathrm{R}^{2}$ values are 0.89, 0.90, and 0.95 for Daysim $1 \mathrm{~m}$ and $2 \mathrm{~m}$, and EnergyPlus, respectively.

Implementation of the simulated solar irradiances on the building surfaces in the CFD simulation suggests that the impact of the solar irradiances on the simulated CFD simulation is more important on the air temperature rather than the air velocity. This study evaluated three different assumptions of using (i) EnergyPlus, (ii) Daysim, and (iii) a fixed temperature as the boundary conditions of CFD simulations. The impacts of using different assumptions is negligible on the simulated air temperature; however, the simulated air temperature showed up to $1.5^{\circ} \mathrm{C}$ and $0.2{ }^{\circ} \mathrm{C}$ between a fixed temperature assumption and EnergyPlus and Daysim and EnergyPlus, respectively. One implication of this results is using EnergyPlus averaged surface results for the outdoor CFD simulations with OpenFOAM could speed up the simulation results.

Overall, this study summarized these benefits and limitations using three simulation tools of (1) EnergyPlus, (2) Daysim, and (3) Radiance for the calculation of the surface solar irradiances. The results could indicate for the simulation of outdoor surface temperatures, use of EnergyPlus enables a direct integration of CFD and outdoor surface boundary conditions since EnergyPlus considers the thermal mass of the building; however, Radiance and Daysim results require using additional physical models to consider the building thermal mass. The results of this study are for the selected urban neighborhoods typically used in the CFD studies where building representations use cubic shapes with a similar height. This is a common approach in the urban canopy models. Overal, based on the result of this study, as a starting point, EnergyPlus results for outdoor solar irradiance provide sufficiently reasonable results for the reviewed urban morphology parameters.

\section{Acknowledgement}

This study is sponsored by the EFRI-1038264/1452045 awards from the National Science Foundation (NSF), Division of Emerging Frontiers in Research and Innovation (EFRI) and the Martin Minta award from the University of Maryland. Authors would like to thank two anonymous reviewers for providing valuable insights that have improved quality of this study.

\section{References}

Arnfield, A. J., \& Grimmond, C. S. B. (1998). An urban canyon energy budget model and its application to urban storage heat flux modeling. Energy and Buildings, 27(1), 61-68. doi: http://dx.doi.org/10.1016/S0378-7788(97)00026-1 
Asawa, T., Hoyano, A., \& Nakaohkubo, K. (2008). Thermal design tool for outdoor spaces based on heat balance simulation using a 3D-CAD system. Building and Environment, 43(12), 2112-2123. doi: http://dx.doi.org/10.1016/j.buildenv.2007.12.007

Ashie, Y., Thanh Ca, V., \& Asaeda, T. (1999). Building canopy model for the analysis of urban climate. Journal of Wind Engineering and Industrial Aerodynamics, 81(1-3), 237-248. doi: http://dx.doi.org/10.1016/S0167-6105(99)00020-3

Baik, J.-J., Park, S.-B., \& Kim, J.-J. (2009). Urban Flow and Dispersion Simulation Using a CFD Model Coupled to a Mesoscale Model. Journal of Applied Meteorology and Climatology, 48(8), 16671681. doi: 10.1175/2009JAMC2066.1

Bueno, B., Norford, L., Pigeon, G., \& Britter, R. (2011). Combining a Detailed Building Energy Model with a Physically-Based Urban Canopy Model. Boundary-Layer Meteorology, 140(3), 471-489. doi: 10.1007/s10546-011-9620-6

Chow, T. T., Lin, Z., \& Wang, Q. W. (2000). Effect of building re-entrant shape on performance of aircooled condensing units. Energy and Buildings, 32(2), 143-152. doi: http://dx.doi.org/10.1016/S0378-7788(99)00048-1

Compagnon, R. (2004). Solar and daylight availability in the urban fabric. Energy and Buildings, 36(4), 321-328. doi: http://dx.doi.org/10.1016/j.enbuild.2004.01.009

Daylighting calculation options. (2015). Retrieved August 2015, 2015 from http://www.designbuilder.co.uk/helpv3/Content/Daylighting\%20Calculation\%200ptions.htm\#A mbient2

de Monte, F. (2000). Transient heat conduction in one-dimensional composite slab. A 'natural' analytic approach. International Journal of Heat and Mass Transfer, 43(19), 3607-3619. doi: http://dx.doi.org/10.1016/S0017-9310(00)00008-9

Defraeye, T., Blocken, B., \& Carmeliet, J. (2010). CFD analysis of convective heat transfer at the surfaces of a cube immersed in a turbulent boundary layer. International Journal of Heat and Mass Transfer, 53(1-3), 297-308. doi: http://dx.doi.org/10.1016/j.ijheatmasstransfer.2009.09.029

Dimoudi, A., Zoras, S., Kantzioura, A., Stogiannou, X., Kosmopoulos, P., \& Pallas, C. (2014). Use of cool materials and other bioclimatic interventions in outdoor places in order to mitigate the urban heat island in a medium size city in Greece. Sustainable Cities and Society, 13(0), 89-96. doi: http://dx.doi.org/10.1016/j.scs.2014.04.003

. EnergyPlus Engineering Reference. (2014).

Fan, L., Borong, L., \& Peng, B. (2013, August 26-28, 2013). Comparison of Simulation Tools for Optimization and Evaluation of Green Building Performance in China. Paper presented at the Proceedings of BS2013: 13th Conference of International Building Performance Simulation Association, Chambéry, France.

Fintikakis, N., Gaitani, N., Santamouris, M., Assimakopoulos, M., Assimakopoulos, D. N., Fintikaki, M., ... Doumas, P. (2011). Bioclimatic design of open public spaces in the historic centre of Tirana, Albania. Sustainable Cities and Society, 1(1), 54-62. doi: http://dx.doi.org/10.1016/j.scs.2010.12.001

Franke, J., Hellsten, A., Schlünzen, H., \& Carissimo, B. (2007). Best practice guideline for the CFD simulation of flows in the urban environment: COST.

Giaconia, C., \& Orioli, A. (2000). On the reliability of ASHRAE conduction transfer function coefficients of walls. Applied Thermal Engineering, 20(1), 21-47. doi: http://dx.doi.org/10.1016/S13594311(99)00005-8

Gracik, S., Heidarinejad, M., Liu, J., \& Srebric, J. (2015). Effect of urban neighborhoods on the performance of building cooling systems. Building and Environment, 90(0), 15-29. doi: http://dx.doi.org/10.1016/i.buildenv.2015.02.037 
Grimmond, C. S. B., Cleugh, H. A., \& Oke, T. R. (1991). An objective urban heat storage model and its comparison with other schemes. Atmospheric Environment. Part B. Urban Atmosphere, 25(3), 311-326. doi: http://dx.doi.org/10.1016/0957-1272(91)90003-W

Gülten, A., Aksoy, U. T., \& Öztop, H. F. Influence of trees on heat island potential in an urban canyon. Sustainable Cities and Society. doi: http://dx.doi.org/10.1016/j.scs.2016.04.006

Huang, H., Ooka, R., \& Kato, S. (2005). Urban thermal environment measurements and numerical simulation for an actual complex urban area covering a large district heating and cooling system in summer. Atmospheric Environment, 39(34), 6362-6375. doi: http://dx.doi.org/10.1016/j.atmosenv.2005.07.018

Kämpf, J. H., Montavon, M., Bunyesc, J., Bolliger, R., \& Robinson, D. (2010). Optimisation of buildings' solar irradiation availability. Solar Energy, 84(4), 596-603. doi: http://dx.doi.org/10.1016/j.solener.2009.07.013

Karan, E., Asadi, S., Mohammadpour, A., Yousefi, M. V., \& Riley, D. (2015, 06/2015). Using building energy simulation and geospatial analysis to determine the building and transportation related energy use. Paper presented at the ASCE International Workshop on Computing in Civil Engineering, Austin, TX.

Kodysh, J. B., Omitaomu, O. A., Bhaduri, B. L., \& Neish, B. S. (2013). Methodology for estimating solar potential on multiple building rooftops for photovoltaic systems. Sustainable Cities and Society, 8(0), 31-41. doi: http://dx.doi.org/10.1016/j.scs.2013.01.002

Liu, J., Heidarinejad, M., Gracik, S., \& Srebric, J. (2015). The impact of exterior surface convective heat transfer coefficients on the building energy consumption in urban neighborhoods with different plan area densities. Energy and Buildings, 86(0), 449-463. doi: http://dx.doi.org/10.1016/i.enbuild.2014.10.062

Liu, J., Heidarinejad, M., Gracik, S., Srebric, J., \& Yu, N. (2015). An indirect validation of convective heat transfer coefficients (CHTCs) for external building surfaces in an actual urban environment. Building Simulation, 8(3), 337-352. doi: 10.1007/s12273-015-0212-0

Liu, J., Srebric, J., \& Yu, N. (2013). Numerical simulation of convective heat transfer coefficients at the external surfaces of building arrays immersed in a turbulent boundary layer. International Journal of Heat and Mass Transfer, 61(0), 209-225. doi: http://dx.doi.org/10.1016/j.ijheatmasstransfer.2013.02.005

Lu, D., \& Weng, Q. (2006). Use of impervious surface in urban land-use classification. Remote Sensing of Environment, 102(1-2), 146-160. doi: http://dx.doi.org/10.1016/j.rse.2006.02.010

Mardaljevic, J. (2011). Ambient calculation: crash course. Paper presented at the 10th Annual International Radiance Workshop 2011, Berkeley, CA. http://www.radianceonline.org/community/workshops/2011-berkeley$\mathrm{ca/presentations/day1/JM} \mathrm{AmbientCalculation.pdf}$

Mirzaei, P. A. (2015). Recent challenges in modeling of urban heat island. Sustainable Cities and Society(0). doi: http://dx.doi.org/10.1016/j.scs.2015.04.001

Mirzaei, P. A., \& Haghighat, F. (2010). Approaches to study Urban Heat Island - Abilities and limitations. Building and Environment, 45(10), 2192-2201. doi: http://dx.doi.org/10.1016/j.buildenv.2010.04.001

Mochida, A., \& Lun, I. Y. F. (2008). Prediction of wind environment and thermal comfort at pedestrian level in urban area. Journal of Wind Engineering and Industrial Aerodynamics, 96(10-11), 14981527. doi: http://dx.doi.org/10.1016/i.jweia.2008.02.033

Moghadam, H., \& Deymeh, S. M. (2015). Determination of optimum location and tilt angle of solar collector on the roof of buildings with regard to shadow of adjacent neighbors. Sustainable Cities and Society, 14(0), 215-222. doi: http://dx.doi.org/10.1016/i.scs.2014.09.009 
Nazarian, N., \& Kleissl, J. (2015). CFD simulation of an idealized urban environment: Thermal effects of geometrical characteristics and surface materials. Urban Climate, 12(0), 141-159. doi: http://dx.doi.org/10.1016/j.uclim.2015.03.002

Oke, T. R., Kalanda, B. D., \& Steyn, D. G. (1981). Parameterization of heat storage in urban areas. Urban Ecology, 5(1), 45-54. doi: http://dx.doi.org/10.1016/0304-4009(81)90020-6

Radiance setting rendering options. (2015). Retrieved August 2015, 2015, from http://radsite.lbl.gov/radiance/man html/rtrace.1.html and http://radsite.lbl.gov/radiance/refer/Notes/rpict options.html

Ramos, G., \& Ghisi, E. (2010). Analysis of daylight calculated using the EnergyPlus programme. Renewable and Sustainable Energy Reviews, 14(7), 1948-1958. doi: http://dx.doi.org/10.1016/j.rser.2010.03.040

Shahrestani, M., Yao, R., \& Cook, G. K. (2013). Characterising the energy performance of centralised HVAC\&amp;R systems in the UK. Energy and Buildings, 62(0), 239-247. doi: http://dx.doi.org/10.1016/j.enbuild.2013.03.016

Spitler, J. D. (2009). Load Calculation Applications Manual I-p Version: American Society of Heating, Refrigerating \& Air-Conditioning Engineers, Incorporated.

Srebric, J., Heidarinejad, M., \& Liu, J. (2015). Building neighborhood emerging properties and their impacts on multi-scale modeling of building energy and airflows. Building and Environment, 91(0), 246-262. doi: http://dx.doi.org/10.1016/j.buildenv.2015.02.031

Stavrakakis, G. M., Tzanaki, E., Genetzaki, V. I., Anagnostakis, G., Galetakis, G., \& Grigorakis, E. (2012). A computational methodology for effective bioclimatic-design applications in the urban environment. Sustainable Cities and Society, 4(0), 41-57. doi: http://dx.doi.org/10.1016/i.scs.2012.05.002

Strømann-Andersen, J., \& Sattrup, P. A. (2011). The urban canyon and building energy use: Urban density versus daylight and passive solar gains. Energy and Buildings, 43(8), 2011-2020. doi: http://dx.doi.org/10.1016/i.enbuild.2011.04.007

Stupka, R., \& Kennedy, C. (2010). Impact of neighborhood density on building energy demand and potential supply via the urban metabolism. Paper presented at the ACEE Summer Study on Energy Efficiency in Buildings.

Takahashi, K., Yoshida, H., Tanaka, Y., Aotake, N., \& Wang, F. (2004). Measurement of thermal environment in Kyoto city and its prediction by CFD simulation. Energy and Buildings, 36(8), 771779. doi: http://dx.doi.org/10.1016/i.enbuild.2004.01.033

Taleb, H., \& Musleh, M. A. (2015). Applying urban parametric design optimisation processes to a hot climate: Case study of the UAE. Sustainable Cities and Society, 14(0), 236-253. doi: http://dx.doi.org/10.1016/j.scs.2014.09.001

Tominaga, Y., Mochida, A., Yoshie, R., Kataoka, H., Nozu, T., Yoshikawa, M., \& Shirasawa, T. (2008). AlJ guidelines for practical applications of CFD to pedestrian wind environment around buildings. Journal of Wind Engineering and Industrial Aerodynamics, 96(10-11), 1749-1761. doi: http://dx.doi.org/10.1016/j.jweia.2008.02.058

Touchaei, A. G., \& Wang, Y. (2015). Characterizing urban heat island in Montreal (Canada)-Effect of urban morphology. Sustainable Cities and Society(0). doi: http://dx.doi.org/10.1016/j.scs.2015.03.005

Xie, X., Huang, Z., Wang, J., \& Xie, Z. (2005). The impact of solar radiation and street layout on pollutant dispersion in street canyon. Building and Environment, 40(2), 201-212. doi: http://dx.doi.org/10.1016/j.buildenv.2004.07.013

Yaghoobian, N., \& Kleissl, J. (2012). An indoor-outdoor building energy simulator to study urban modification effects on building energy use - Model description and validation. Energy and Buildings, 54(0), 407-417. doi: http://dx.doi.org/10.1016/j.enbuild.2012.07.019 